Supporting Information to

\title{
Mechanistic effect modeling approach for the extrapolation of species sensitivity
}

\author{
André Gergs ${ }^{1,2, *}$, Kim J. Rakel ${ }^{1}$, Dino Liesy ${ }^{3}$, Armin Zenker ${ }^{4}$, Silke Classen ${ }^{1}$
}

${ }^{1}$ Research Institute for Ecosystem Analysis and Assessment (gaiac), Kackertstrasse 10, 52072 Aachen, Germany

${ }^{2}$ current address: Bayer AG, Alfred-Nobel-Straße 50, 40789 Monheim am Rhein, Germany

${ }^{3}$ University of Koblenz-Landau, Fortstraße 7, 76829 Landau, Germany

${ }^{4}$ Institute for Ecopreneurship, School of Life Sciences, University of Applied Sciences and Arts Northwestern Switzerland, Hofackerstrasse 340, 4132 Muttenz, Switzerland

*corresponding author: andre.gergs@bayer.com

26 pages, 23 figures, 17 tables 


\section{Content}

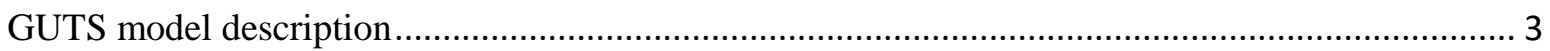

Parameter estimation, statistical analyses and model simulations .................................................. 3

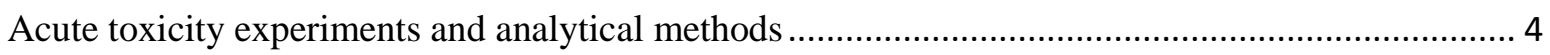

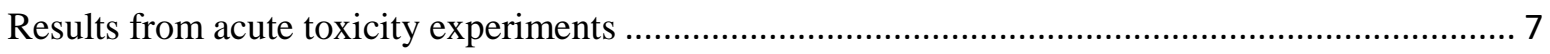

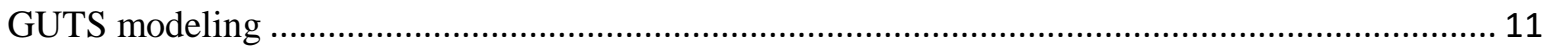

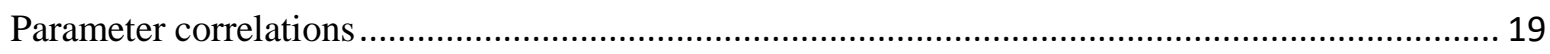

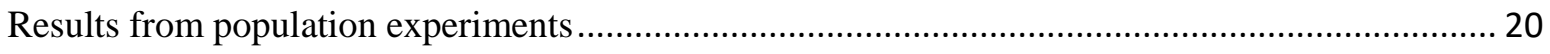

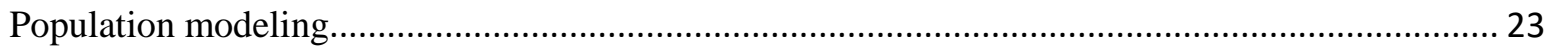

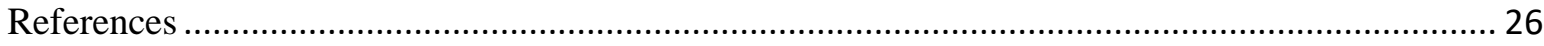




\section{GUTS model description}

The change in the scaled internal concentration $\mathrm{C}_{\mathrm{i}}$ * is based on the exposure concentration $C_{w}$ and the dominant rate constant $k_{d}$, which is also called the elimination rate constant (Equation 1). The dominant rate $k_{d}$ is scaled with the surface-to-volume ratio $1 / L$, relative to the maximum ratio $1 / \mathrm{Lm}$, and therefore, the factor $L m / L$ is used, where $L$ is the length of the animal, $L_{m}$ denotes the maximum length of the species and $k_{d}{ }^{*}$ is the scaled dominant rate (Equation 2). The change in hazard $H$ is calculated based on the threshold concentration $z$, the killing rate $k_{k}$, and the background hazard rate constant $h_{b}$ (Equation 3). We assumed that initially, at $\mathrm{t}=0$, the internal concentration and the hazard are equal to zero. The model's rate constants are corrected for ambient temperature $T$ by multiplication with the Arrhenius temperature function $F_{T}$ (Equation 4) which is based on the Arrhenius temperature $T_{A}$, and the reference temperature $T_{r e f}$. The survival probability $S$ is given in Equation 5 .

$$
\begin{array}{ll}
\frac{C_{i}^{*}}{d t}=k_{d}\left(C_{w}-C_{i}^{*}\right) & \text { (Equation 1) } \\
\text { assuming } \frac{C_{i}}{d t}=k_{a} C_{w}-k_{e} C_{i} & \text { with } k_{a}=k_{e} B C F \text { and } B C F=1 \\
k_{d}=k_{d}^{*} \frac{L_{m}}{L} & \text { (Equation 2) } \\
\frac{d H}{d t}=k_{k} \max \left(C_{i}^{*}-z, 0\right)+h_{b} & \text { (Equation 3) } \\
F_{T}=\exp \left(\frac{T_{A}}{T_{r e f}}-\frac{T_{A}}{T}\right) & \text { (Equation 4) } \\
S(t)=\exp (-\mathrm{H}(\mathrm{t})) & \text { (Equation 5) }
\end{array}
$$

\section{Parameter estimation, statistical analyses and model simulations}

GUTS parameter estimation and likelihood profiling was done using the GUTS package in the BYOM platform; for details see ref 1 . The GUTS package in the BYOM platform was subsequently used to calculate $\mathrm{LC}_{50} \mathrm{~s}(96 \mathrm{~h})$. For each of the species, two different $\mathrm{LC}_{50}(96 \mathrm{~h})$ values have been computed. The first $\mathrm{LC}_{50}$ was based on the original parameter estimates, while the second was correct for ambient temperature. For temperature correction, the rate constants of GUTS, i.e. the dominant rate $\mathrm{k}_{\mathrm{d}}$ and the killing rate $\mathrm{k}_{\mathrm{k}}$, were multiplied with the temperature correction factor (Equation 4):

$$
\begin{aligned}
& k_{d}(T)=k_{d, \text { ref }} F_{T}(T) \quad \text { (Equation 6) } \\
& k_{k}(T)=k_{k, \text { ref }} F_{T}(T) \quad \text { (Equation 7) }
\end{aligned}
$$

We calculated GUTS rate constants and a temperature corrected $\mathrm{LC}_{50}$ for a temperature of $20^{\circ} \mathrm{C}$, based on the original test temperature as a reference temperature and the Arrhenius temperature (Equations 6 and 7). This approach is illustrated in Figure 1 of main text. Parameter values for the Arrhenius temperature, which might vary across species, were derived from the 'add-my-pet' collection ${ }^{2}$ which is a database of code, data and DEB model parameters. For both regular $\mathrm{LC}_{50} \mathrm{~s}$ and temperature corrected LC $_{50}$, SSDs were constructed using the MOSAIC SSD $_{\text {platform. }}{ }^{3}$ Only arthropod species were included in the SSD (see Figure 2 in the main text). 
We analyzed linear correlations among GUTS parameters for the different species (see Figure 3 of the main text). To account for the different life stages or sizes used for the different test species, we scaled the dominant rate constant $\mathrm{k}_{\mathrm{d}}$ with the relative surface-to-volume ratio of species (Equation 2). Moreover, we evaluated the correlation of the GUTS threshold parameters with the metabolic rates of the species, as suggested by Baas and Kooijman. ${ }^{4}$ The metabolic rate, here the volume-specific somatic maintenance rate $\mathrm{p}_{\mathrm{M}}$, which is a DEB parameter, was taken from the add-my-pet collection. ${ }^{2}$ Parameter values were log transformed before being processed in linear regression analyses.

IBM simulations were carried out to mimic population experiments, as described below. This step was performed to test the predictive capability of the regression analysis for the GUTS parameters in a risk assessment context. Therefore, we repeated the analysis by removing D. magna from the data set and made predictions for the GUTS parameters based on linear regressions and the metabolic rate $\mathrm{p}_{\mathrm{M}}$ for D. magna: The metabolic rate $\mathrm{p}_{\mathrm{M}}$ for Daphnia magna was derived from the species specific entry in the add-my-pet database ${ }^{2}$. After applying the logarithm to the metabolic rate $\mathrm{pM}$, the log value of threshold $\mathrm{z}$ was determined by applying the linear regression (Figure S15, right panel). Having the log threshold $\mathrm{z}$ calculated, the log killing rate $\mathrm{k}_{\mathrm{k}}$ was derived accordingly using the regression shown in Figure S15, left panel. The calculated log killing rate $\mathrm{k}_{\mathrm{k}}$ subsequently allowed the derivation of the $\log$ dominant rate $k_{d}$ value (Figure S15, center). Regression parameters are listed in Table S14. The antilogarithm of regression results for all parameters (kd, kk and $\mathrm{z}$ ) were used for the IBM simulations with Daphnia magna. Simulations based on the actual GUTS parameterization for D. magna at $20^{\circ} \mathrm{C}$ served as a reference.

All modeling was based on measured chlorpyrifos concentrations and a temperature-dependent dissipation time (see section below). A negative exponential function was used to calculate the temperature-specific half-life of chlorpyrifos in our experimental settings (Figure S1).

\section{Acute toxicity experiments and analytical methods}

Acute toxicity tests were carried out with Daphnia magna and five macroinvertebrate species: Asellus aquaticus, Chaoborus crystallinus, Cloeon dipterum, Epeorus assimilis, Rhithrogena semicolorata, and Potamopyrgus antipodarum. Chlorpyrifos was used as a model substance for the study. Larvae of C. dipterum and C. crystallinus were derived from the gaiac mesocosm facility, whereas larvae of the two other mayfly species Rhithrogena semicolorata and Epeorus assimilis were collected from unpolluted stream stretches of relatively good structural quality in the area of Aachen, Germany. A. aquaticus, D. magna and $P$. antipodarum test specimens were derived from laboratory stocks established at the Research Institute gaiac. The acute toxicity tests with different species were performed using the overall same test design, with the exception of temperature (see Table S12) and concentration range (see legends of Figures S1-10), which were chosen to account for speciespreferences/collection-temperature and sensitivity, respectively. Slight changes to the test protocol were, however, made for P. antipodarum, see Table S10. Field-collected organisms were tested in the laboratory at ambient temperatures similar to those in the field at collection time. Organisms were acclimatized to laboratory conditions for at least 4 days prior to testing and during this period were provided with food collected from their original sites.

We additionally tested acute toxicity in D. magna at different temperatures (see Table 12). Prior to the testing at temperatures that were different from culture conditions of $20^{\circ} \mathrm{C}, \mathrm{D}$. magna specimens were kept at the test temperature for at least two weeks. Tested neonates ( $<24$ hours) were derived from $2^{\text {nd }}$ and $3^{\text {rd }}$ broods of the mothers cultured at the respective temperature. The $D$. magna toxicity test at $20^{\circ} \mathrm{C}$ was performed twice.

Tests were carried out during a period of 96 hours, without any addition of food, under a light:dark period of 16:8h and with static chlorpyrifos exposure. For the control and each exposure 
concentration, 30 individuals (divided into 6 replicates) were tested. Test animals were checked for mobility on 13 occasions at pre-defined intervals until test termination. Body lengths of tested specimens were measured under magnification, except for D. magna where siblings were measured at the start of the experiment.

The stock solution with chlorpyrifos (99\% purity, CAS number: 2921-88-2, LGC Standards GmbH, Wesel, Germany) was prepared according to Barata et al., ${ }^{5}$ with the exception that the solution was stirred for 24 hours in darkness to replace sonication. This stock solution was used to prepare test solutions. Analytical samples were taken at the initiation of the test with each organism. For the test with $D$. magna and all four temperature regimes, samples were additionally taken at the end of the test. Samples were stored at $-20^{\circ} \mathrm{C}$ before being analyzed.

All stock solutions and all of the exposure concentrations used in the tests with D. magna were verified analytically. As the percentage recovery in these analyses were rather constant, we only verified the two highest test concentrations in the tests with other species. The lower concentrations in those tests were estimated based on percent deviation from nominal concentrations.

A liquid chromatography-mass spectrometry system consisting of an Agilent (Waldbronn, Germany) 1260 Infinity HPLC system (binary pump, degasser, auto sampler) coupled to a 6420 Triple Quad LC/MS equipped with an electrospray ionization (Agilent, Waldbronn, Germany) was used for the detection and quantification of chlorpyrifos. The chromatographic separation was conducted using a Zorbax SB-C8 Rapid Resolution HT column (50 mm x $2.1 \mathrm{~mm}, 1.8 \mathrm{um}$ particle size) from Agilent Technologies (Wilmington, DE, USA) at a column temperature of $40^{\circ} \mathrm{C}$.

For the analysis in positive ion mode, a binary gradient mixture consisting of $0.1 \%(\mathrm{v} / \mathrm{v})$ formic acid and 5\% acetonitrile in HPLC grade water (eluent A) and $0.1 \%(\mathrm{v} / \mathrm{v})$ formic acid and 5\% HPLC grade water in acetonitrile (eluent B) was used at a flow rate of $0.6 \mathrm{~mL} / \mathrm{min}$. The elution gradient started with $100 \%$ of eluent A. Isocratic conditions were held for $1 \mathrm{~min}$ and then eluent B increased to $30 \%$ within $3.5 \mathrm{~min}$. Eluent B further increased to $100 \%$ within $4 \mathrm{~min}$ and isocratic conditions were held for $1.5 \mathrm{~min}$. Afterwards, the system was set back to initial conditions within $5 \mathrm{~min}$.

The sample injection volume was set to $10 \mu \mathrm{L}$. By the direct injection of stock solutions with a concentration of $10 \mu \mathrm{g} / \mathrm{mL}$, fragmentor voltage and collision energy were optimized. Protonated $([\mathrm{M}+\mathrm{H}]+)$ molecular ion were selected as precursor ion. Two transitions were selected, whereby the intense product ion was used for quantification and the secondary product ion was used as qualifier. As scan type dynamic multiple reaction monitoring (MRM) was used. Source parameters were set to 4 $\mathrm{kV}$ in positive mode for capillary voltage, desolvation gas temperature was set to $300^{\circ} \mathrm{C}$, desolvation gas flow to $11 \mathrm{~L} / \mathrm{min}$ and the nebulizer pressure to $50 \mathrm{psi}$. The MRM transitions, fragmentor voltage and collision energies for chlorpyrifos are presented in Table S1. The linearity of the eleven point calibration curve in the range of $0.05-1.8 \mathrm{ug} / \mathrm{L}$ was calculated with a correlation coefficient (R2) of 0.995. To determine the lowest concentration of chlorpyrifos which is detected in presence of possible matrix effects, tab water samples $(n=7)$ spiked with the analyte were prepared and measured as described above. The limit of detection (LOD) was $0.05 \mathrm{ug} / \mathrm{L}$ and the limit of quantitation (LOQ) was $0.09 \mu \mathrm{g} / \mathrm{L}$.

Table S1. Parent compound and its transformation products, substance-specific MS/MS parameters: precursor ion, main product ion (quantifier), secondary product ion (qualifier), collision energy, fragmentor voltage.

\begin{tabular}{llll}
\hline Precursor ion $(\mathrm{m} / \mathrm{z})$ & Product ion $(\mathrm{m} / \mathrm{z})$ & Fragmentor voltage & Collision energy \\
\hline $350[\mathrm{M}+\mathrm{H}]$ & 293.9 & 100 & 13 \\
$350[\mathrm{M}+\mathrm{H}]$ & $\mathbf{1 9 7 . 9}$ & 100 & 18 \\
\hline
\end{tabular}




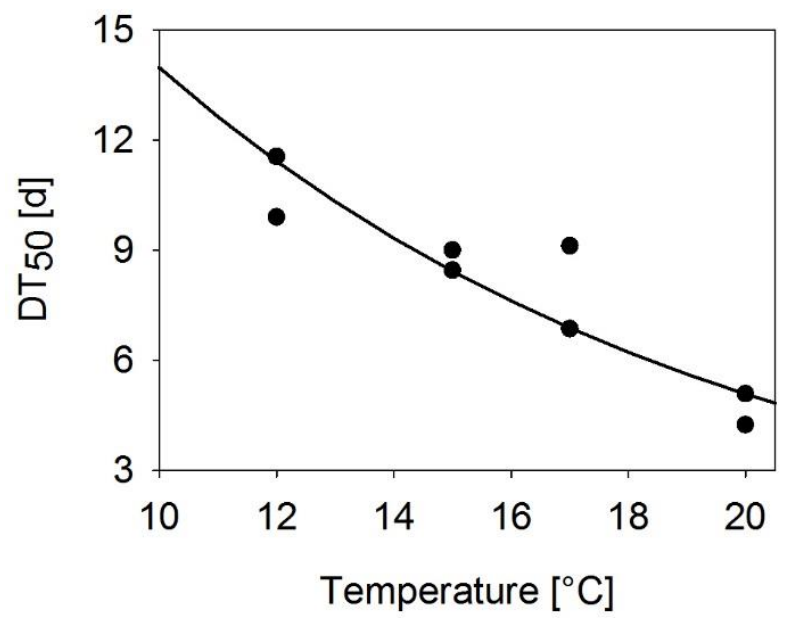

Figure S1: Chemical half-life $\left(\mathrm{DT}_{50}\right)$ as a function of temperature based on the analytical results from the two highest chlorpyrifos concentrations in the toxicity tests with Daphnia magna. Dots represent data, the empirical regression (line) is: $\mathrm{y}=38.4 \exp (-0.101 \mathrm{x}), \mathrm{r}^{2}=0.836$. 


\section{Results from acute toxicity experiments}

Table S2: Number of mobile individuals observed in the acute toxicity test with Asellus aquaticus

\begin{tabular}{ccccccc}
\hline Time $[\mathrm{h}]$ & \multicolumn{5}{c}{ Number of mobile individuals $[\#]$} \\
Concentration $[\mu \mathrm{g} / \mathrm{L}]:$ & 0 & 1.86 & 4.34 & 8.25 & 10.78 & 13.48 \\
\hline 0 & 30 & 30 & 30 & 30 & 30 & 30 \\
4 & 30 & 30 & 29 & 30 & 30 & 28 \\
8 & 30 & 30 & 29 & 28 & 28 & 25 \\
24 & 30 & 30 & 23 & 13 & 4 & 1 \\
28 & 30 & 30 & 17 & 7 & 0 & 1 \\
32 & 30 & 30 & 7 & 2 & 0 & 1 \\
48 & 30 & 22 & 0 & 0 & 0 & 0 \\
52 & 30 & 21 & 0 & 0 & 0 & 0 \\
56 & 30 & 21 & 0 & 0 & 0 & 0 \\
72 & 30 & 20 & 0 & 0 & 0 & 0 \\
76 & 30 & 20 & 0 & 0 & 0 & 0 \\
80 & 30 & 20 & 0 & 0 & 0 & 0 \\
96 & 30 & 20 & 0 & 0 & 0 & 0 \\
\hline
\end{tabular}

Table S3: Number of mobile individuals observed in the acute toxicity test with Chaoborus crystallinus

\begin{tabular}{cccccccc}
\hline Time $[\mathrm{h}]$ & \multicolumn{7}{c}{ Number of mobile individuals [\#] } \\
Concentration $[\mu \mathrm{g} / \mathrm{L}]:$ & 0 & 0.174 & 0.330 & 0.626 & 0.910 & 2.225 & 4.36 \\
\hline 0 & 30 & 30 & 30 & 30 & 30 & 30 & 30 \\
4 & 30 & 30 & 30 & 30 & 30 & 30 & 30 \\
20 & 30 & 30 & 30 & 28 & 30 & 29 & 26 \\
23 & 30 & 30 & 30 & 28 & 24 & 22 & 18 \\
28 & 29 & 30 & 30 & 23 & 21 & 19 & 17 \\
44 & 29 & 30 & 28 & 18 & 18 & 11 & 8 \\
47 & 29 & 30 & 27 & 17 & 17 & 11 & 8 \\
52 & 29 & 30 & 26 & 17 & 17 & 11 & 8 \\
68 & 29 & 30 & 24 & 15 & 12 & 8 & 4 \\
71 & 29 & 30 & 24 & 14 & 12 & 8 & 4 \\
76 & 29 & 30 & 23 & 13 & 10 & 8 & 4 \\
92 & 29 & 30 & 23 & 13 & 9 & 5 & 3 \\
96 & 29 & 30 & 22 & 12 & 6 & 4 & 3 \\
\hline
\end{tabular}

Table S4: Number of mobile individuals observed in the acute toxicity test with Cloeon dipterum

\begin{tabular}{ccccccc}
\hline Time $[\mathrm{h}]$ & \multicolumn{5}{c}{ Number of mobile individuals [\#] } \\
Concentration $[\mu \mathrm{g} / \mathrm{L}]:$ & 0 & 0.480 & 0.769 & 1.19 & 2.67 & 3.59 \\
\hline 0 & 30 & 30 & 30 & 30 & 30 & 30 \\
5 & 30 & 30 & 30 & 30 & 30 & 30 \\
21 & 30 & 30 & 29 & 30 & 30 & 30 \\
24 & 30 & 30 & 29 & 30 & 30 & 30 \\
29 & 30 & 30 & 29 & 30 & 29 & 28 \\
45 & 30 & 30 & 29 & 26 & 23 & 12 \\
48 & 30 & 29 & 29 & 24 & 20 & 9 \\
53 & 30 & 29 & 29 & 24 & 19 & 9 \\
69 & 30 & 28 & 27 & 10 & 9 & 1 \\
72 & 30 & 28 & 25 & 9 & 6 & 0 \\
77 & 30 & 28 & 24 & 5 & 4 & 0 \\
93 & 30 & 28 & 20 & 2 & 1 & 0 \\
96 & 30 & 28 & 19 & 1 & 1 & 0 \\
\hline
\end{tabular}


Table S5a: Number of mobile individuals observed in the acute toxicity test with Daphnia magna at $20^{\circ} \mathrm{C}$, first experiment.

\begin{tabular}{ccccccc}
\hline Time $[\mathrm{h}]$ & \multicolumn{5}{c}{ Number of mobile individuals [\#] } \\
Concentration $[\mu \mathrm{g} / \mathrm{L}]:$ & 0 & 0.480 & 1.11 & 1.75 & 2.32 & 3.12 \\
\hline 0 & 30 & 30 & 30 & 30 & 30 & 30 \\
5 & 30 & 30 & 30 & 30 & 30 & 30 \\
20 & 30 & 30 & 14 & 3 & 0 & 0 \\
24 & 30 & 22 & 5 & 0 & 0 & 0 \\
29 & 30 & 20 & 5 & 0 & 0 & 0 \\
44 & 30 & 1 & 0 & 0 & 0 & 0 \\
48 & 30 & 1 & 0 & 0 & 0 & 0 \\
53 & 30 & 1 & 0 & 0 & 0 & 0 \\
68 & 30 & 0 & 0 & 0 & 0 & 0 \\
72 & 30 & 0 & 0 & 0 & 0 & 0 \\
77 & 30 & 0 & 0 & 0 & 0 & 0 \\
92 & 30 & 0 & 0 & 0 & 0 & 0 \\
96 & 30 & 0 & 0 & 0 & 0 & 0 \\
\hline
\end{tabular}

Table S5b: Number of mobile individuals observed in the acute toxicity test with Daphnia magna at $20^{\circ} \mathrm{C}$, second experiment

\begin{tabular}{ccccccc}
\hline Time $[\mathrm{h}]$ & \multicolumn{5}{c}{ Number of mobile individuals $[\#]$} & \\
Concentration $[\mu \mathrm{g} / \mathrm{L}]:$ & 0 & 0.480 & 1.11 & 1.75 & 2.32 & 3.12 \\
\hline 0 & 30 & 30 & 30 & 30 & 30 & 30 \\
5 & 30 & 30 & 30 & 30 & 30 & 30 \\
20 & 30 & 30 & 30 & 30 & 30 & 30 \\
24 & 30 & 30 & 28 & 18 & 17 & 12 \\
29 & 30 & 30 & 25 & 14 & 11 & 3 \\
44 & 30 & 27 & 21 & 9 & 5 & 0 \\
48 & 30 & 7 & 0 & 0 & 0 & 0 \\
52 & 30 & 3 & 0 & 0 & 0 & 0 \\
68 & 30 & 1 & 0 & 0 & 0 & 0 \\
72 & 30 & 0 & 0 & 0 & 0 & 0 \\
77 & 29 & 0 & 0 & 0 & 0 & 0 \\
92 & 28 & 0 & 0 & 0 & 0 & 0 \\
96 & 28 & 0 & 0 & 0 & 0 & 0 \\
\hline
\end{tabular}

Table S6: Number of mobile individuals observed in the acute toxicity test with Daphnia magna at $17.2^{\circ} \mathrm{C}$

\begin{tabular}{ccccccc}
\hline Time $[\mathrm{h}]$ & \multicolumn{5}{c}{ Number of mobile individuals [\#] } \\
Concentration $[\mu \mathrm{g} / \mathrm{L}]:$ & 0 & 0.480 & 1.01 & 1.18 & 2.11 & 3.11 \\
\hline 0 & 30 & 30 & 30 & 29 & 30 & 29 \\
5 & 30 & 30 & 30 & 29 & 30 & 28 \\
20 & 30 & 29 & 22 & 14 & 4 & 0 \\
24 & 30 & 27 & 17 & 4 & 0 & 0 \\
29 & 30 & 22 & 15 & 0 & 0 & 0 \\
44 & 30 & 4 & 1 & 0 & 0 & 0 \\
48 & 30 & 1 & 0 & 0 & 0 & 0 \\
53 & 30 & 0 & 0 & 0 & 0 & 0 \\
68 & 30 & 0 & 0 & 0 & 0 & 0 \\
72 & 30 & 0 & 0 & 0 & 0 & 0 \\
77 & 30 & 0 & 0 & 0 & 0 & 0 \\
92 & 30 & 0 & 0 & 0 & 0 & 0 \\
96 & 30 & 0 & 0 & 0 & 0 & 0 \\
\hline
\end{tabular}


Table S7: Number of mobile individuals observed in the acute toxicity test with Daphnia magna at $14.9^{\circ} \mathrm{C}$

\begin{tabular}{ccccccc}
\hline Time $[\mathrm{h}]$ & \multicolumn{5}{c}{ Number of mobile individuals [\#] } \\
Concentration $[\mu \mathrm{g} / \mathrm{L}]:$ & 0 & 0.480 & 1.06 & 1.75 & 2.29 & 3.20 \\
\hline 0 & 30 & 30 & 30 & 30 & 30 & 30 \\
5 & 30 & 30 & 30 & 30 & 30 & 30 \\
20 & 30 & 30 & 29 & 25 & 16 & 3 \\
24 & 30 & 30 & 27 & 9 & 7 & 1 \\
29 & 30 & 29 & 17 & 4 & 1 & 0 \\
44 & 30 & 7 & 0 & 0 & 0 & 0 \\
48 & 30 & 4 & 0 & 0 & 0 & 0 \\
53 & 30 & 1 & 0 & 0 & 0 & 0 \\
68 & 30 & 0 & 0 & 0 & 0 & 0 \\
72 & 30 & 0 & 0 & 0 & 0 & 0 \\
77 & 30 & 0 & 0 & 0 & 0 & 0 \\
92 & 30 & 0 & 0 & 0 & 0 & 0 \\
96 & 30 & 0 & 0 & 0 & 0 & 0 \\
\hline
\end{tabular}

Table S8: Number of mobile individuals observed in the acute toxicity test with Daphnia magna at $11.5^{\circ} \mathrm{C}$

\begin{tabular}{ccccccc}
\hline Time $[\mathrm{h}]$ & \multicolumn{5}{c}{ Number of mobile individuals [\#] } \\
Concentration $[\mu \mathrm{g} / \mathrm{L}]:$ & 0 & 0.480 & 1.03 & 1.81 & 2.39 & 3.19 \\
\hline 0 & 30 & 30 & 30 & 30 & 30 & 30 \\
5 & 30 & 30 & 30 & 30 & 30 & 30 \\
20 & 30 & 30 & 30 & 30 & 30 & 29 \\
24 & 30 & 30 & 30 & 30 & 28 & 19 \\
29 & 30 & 30 & 30 & 27 & 16 & 4 \\
44 & 30 & 20 & 12 & 1 & 0 & 0 \\
48 & 30 & 14 & 10 & 1 & 0 & 0 \\
53 & 30 & 9 & 9 & 0 & 0 & 0 \\
68 & 30 & 0 & 0 & 0 & 0 & 0 \\
72 & 30 & 0 & 0 & 0 & 0 & 0 \\
77 & 30 & 0 & 0 & 0 & 0 & 0 \\
92 & 30 & 0 & 0 & 0 & 0 & 0 \\
96 & 30 & 0 & 0 & 0 & 0 & 0 \\
\hline
\end{tabular}

Table S9: Number of mobile individuals observed in the acute toxicity test with Epeorus assimilis

\begin{tabular}{cccccccc}
\hline Time $[\mathrm{h}]$ & \multicolumn{7}{c}{ Number of mobile individuals [\#] } \\
Concentration $[\mu \mathrm{g} / \mathrm{L}]:$ & 0 & 0.253 & 0.480 & 0.769 & 1.19 & 1.60 & 3.52 \\
\hline 0 & 30 & 30 & 30 & 29 & 30 & 30 & 30 \\
5 & 30 & 30 & 30 & 29 & 29 & 30 & 30 \\
20 & 29 & 30 & 27 & 21 & 11 & 6 & 3 \\
24 & 29 & 30 & 26 & 19 & 10 & 4 & 3 \\
29 & 29 & 30 & 26 & 13 & 2 & 2 & 2 \\
44 & 28 & 29 & 16 & 1 & 1 & 0 & 2 \\
48 & 27 & 25 & 15 & 0 & 1 & 0 & 2 \\
53 & 25 & 24 & 14 & 0 & 1 & 0 & 2 \\
68 & 24 & 23 & 7 & 0 & 0 & 0 & 2 \\
72 & 23 & 23 & 7 & 0 & 0 & 0 & 2 \\
77 & 23 & 23 & 6 & 0 & 0 & 0 & 2 \\
92 & 22 & 23 & 5 & 0 & 0 & 0 & 2 \\
96 & 22 & 23 & 5 & 0 & 0 & 0 & 2 \\
\hline
\end{tabular}


Table S10: Number of mobile individuals observed in the acute toxicity test with Rhithrogena semicolorata

\begin{tabular}{cccccccc}
\hline Time $[\mathrm{h}]$ & \multicolumn{7}{c}{ Number of mobile individuals [\#] } \\
Concentration $[\mu \mathrm{g} / \mathrm{L}]:$ & 0 & 0.030 & 0.480 & 0.769 & 1.19 & 2.52 & 3.45 \\
\hline 0 & 30 & 30 & 30 & 30 & 30 & 30 & 30 \\
5 & 30 & 30 & 30 & 30 & 30 & 30 & 30 \\
20 & 29 & 30 & 29 & 30 & 30 & 30 & 29 \\
24 & 29 & 30 & 29 & 30 & 30 & 30 & 29 \\
29 & 29 & 30 & 29 & 30 & 30 & 29 & 27 \\
44 & 29 & 29 & 29 & 30 & 28 & 24 & 19 \\
48 & 28 & 29 & 29 & 30 & 28 & 23 & 19 \\
53 & 27 & 29 & 29 & 30 & 26 & 22 & 16 \\
68 & 25 & 28 & 29 & 26 & 23 & 16 & 9 \\
72 & 25 & 27 & 28 & 25 & 18 & 13 & 5 \\
77 & 25 & 27 & 28 & 25 & 16 & 12 & 5 \\
92 & 25 & 27 & 28 & 21 & 14 & 6 & 4 \\
96 & 25 & 27 & 27 & 19 & 12 & 5 & 4 \\
\hline
\end{tabular}

Table S11: Number of mobile individuals observed in the acute toxicity test with Potamopyrgus antipodarum

\begin{tabular}{ccccccc}
\hline Time $[\mathrm{h}]$ & \multicolumn{5}{c}{ Number of mobile individuals [\#] } \\
Concentration $[\mu \mathrm{g} / \mathrm{L}]:$ & 0 & 48.3 & 74.5 & 117.1 & 240 & 294 \\
\hline 0 & 30 & 30 & 30 & 30 & 30 & 25 \\
1 & 30 & 30 & 30 & 30 & 30 & 25 \\
5 & 30 & 30 & 30 & 30 & 30 & 18 \\
21 & 30 & 30 & 11 & 1 & 1 & 1 \\
24 & 30 & 30 & 11 & 0 & 0 & 1 \\
29 & 30 & 30 & 11 & 0 & 0 & 1 \\
45 & 30 & 28 & 11 & 8 & 2 & 4 \\
48 & 30 & 28 & 11 & 8 & 2 & 4 \\
53 & 30 & 29 & 9 & 8 & 0 & 1 \\
69 & 30 & 29 & 6 & 1 & 0 & 4 \\
72 & 30 & 29 & 9 & 2 & 0 & 4 \\
77 & 30 & 29 & 8 & 5 & 1 & 5 \\
93 & 30 & 27 & 7 & 4 & 1 & 7 \\
96 & 30 & 27 & 7 & 6 & 1 & 7 \\
\hline
\end{tabular}




\section{GUTS modeling}

Table S12: Body length as measured for the test organisms in the toxicity experiments, and auxiliary parameters taken from the Add-My-Pet collection*, $\mathrm{p}_{\mathrm{M}}$ is given for a reference temperature of $20^{\circ} \mathrm{C}$

\begin{tabular}{lcccc}
\hline Test organism & Measured length $[\mathrm{cm}]$ & Maximum length $[\mathrm{cm}]^{*}$ & $\mathrm{p}_{\mathrm{M}}\left[\mathrm{J} / \mathrm{d} \mathrm{cm}^{\wedge} 3\right]^{*}$ & $\mathrm{~T}_{\mathrm{A}}[\mathrm{K}]^{*}$ \\
\hline Asellus aquaticus & 0.7 & 1.024 & 210 & 8000 \\
Ceriodaphnia dubia & 0.036 & 0.0983 & 1306 & 8000 \\
Chaoborus crystallinus & 1.07 & 1.6 & 25.0 & 8000 \\
Cloeon dipterum & 0.717 & 0.93 & 518 & 8000 \\
Daphnia magna & 0.099 & 0.502 & 1453 & 6400 \\
Epeorus assimilis & 0.807 & 2 & 494 & 9391 \\
Gammarus fossarum & 1.32 & 1.47 & 464 & 7769 \\
Potamopyrgus antipodarum & 0.37 & 0.65 & 37.8 & 8000 \\
Pimephales promelas & 2 & 10.2 & 209 & 6000 \\
Rhithrogena semicolorata & 0.76 & 1.15 & 521 & 11720 \\
\hline
\end{tabular}

* https://www.bio.vu.nl/thb/deb/deblab/add_my_pet/index.html; accessed on 01/14/ 2018

Table S13: Ambient temperature in toxicity experiments and estimated GUTS parameters for the different test species. Daphnia magna parameters for $11.5,14.9,17.2^{\circ} \mathrm{C}$ have not been used in SSD and cross-species analysis.

\begin{tabular}{lcllll}
\hline Test organism & Temperature $\left[{ }^{\circ} \mathrm{C}\right]$ & $\mathrm{k}_{\mathrm{d}}[1 / \mathrm{d}]$ & $\mathrm{z}$ & $\mathrm{k}_{\mathrm{k}}[1 / \mathrm{d}]$ & $\mathrm{h}_{\mathrm{b}}[1 / \mathrm{d}]$ \\
\hline Asellus aquaticus & 20 & 0.926 & 1.11 & 0.848 & 0.00601 \\
Ceriodaphnia dubia & 25 & 0.00192 & 0.000610 & 1080 & 0.00815 \\
Chaoborus crystallinus & 20 & 0.875 & 0.0893 & 0.467 & 0.000251 \\
Cloeon dipterum & 20 & 0.000150 & 0.000202 & 2050 & 0.00870 \\
Daphnia magna & 11.5 & 0.0000238 & 0.0000157 & 81000 & 0 \\
Daphnia magna & 14.9 & 0.0000305 & 0.0000139 & 93500 & 0 \\
Daphnia magna & 17.2 & 0.0000386 & 0.0000169 & 15400 & 0 \\
Daphnia magna & 20 & 0.0000460 & 0.0000161 & 17600 & 0 \\
Epeorus assimilis & 12 & 0.00272 & 0.000260 & 320 & 0.0681 \\
Gammarus fossarum & 12 & 0.000742 & 0.00103 & 287 & 0.00606 \\
Potamopyrgus antipodarum & 20 & 1.19 & 27.5 & 0.0798 & 0.0805 \\
Pimephales promelas & 25.1 & 240 & 125 & 0.00300 & 0.00379 \\
Rhithrogena semicolorata & 12 & 0.000106 & 0.000130 & 1190 & 0.0222 \\
\hline
\end{tabular}


Table S13 (continued): Confidence limits (CL) of estimated GUTS parameters.

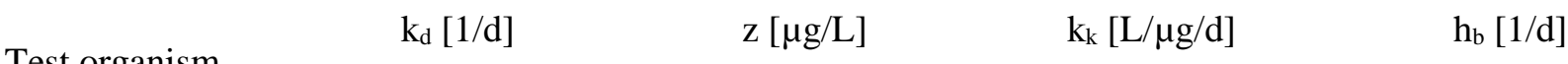

Test organism lower CL upper CL lower CL upper CL lower CL upper CL lower CL upper CL

\begin{tabular}{lcccccccc}
\hline A. aquaticus & 0.658 & 1.27 & 0.914 & 1.26 & 0.606 & 1.18 & 0.000357 & 0.0259 \\
C. dubia & 0.00177 & 0.00211 & 0.000538 & 0.000671 & 677 & 1660 & 0.00326 & 0.0164 \\
C. crystallinus & 0.644 & 1.23 & 0.0259 & 0.136 & 0.380 & 0.566 & 0.000371 & 0.0228 \\
C. dipterum & 0.000138 & 0.000164 & 0.000176 & 0.000226 & 1660 & 2500 & 0.00233 & 0.0221 \\
D. magna $11.5^{\circ} \mathrm{C}$ & 0.0000204 & 0.0000242 & 0.0000145 & 0.0000171 & 25600 & 82800 & 0 & 0.0105 \\
D. magna $14.9^{\circ} \mathrm{C}$ & 0.0000282 & 0.0000330 & 0.0000122 & 0.0000155 & 78500 & 111000 & 0 & 0.0107 \\
D. magna $17.2^{\circ} \mathrm{C}$ & 0.0000373 & 0.0000455 & 0.0000121 & 0.0000176 & 128000 & 191000 & 0 & 0.0598 \\
D. magna $20^{\circ} \mathrm{C}$ & 0.0000302 & 0.0000462 & 0.0000159 & 0.0000206 & 16600 & 177000 & 0 & 0.00678 \\
E. assimilis & 0.00227 & 0.00297 & 0.0000318 & 0.000466 & 257 & 351 & 0.0336 & 0.114 \\
G. fossarum & 0.000680 & 0.000811 & 0.000902 & 0.00115 & 219 & 369 & 0.00299 & 0.0107 \\
P. antipodarum & 0.138 & 2.69 & 4.25 & 40.6 & 0.0381 & 0.521 & 0.0291 & 0.170 \\
P. promelas & 6.56 & 100 & 116 & 130 & 0.00276 & 0.00379 & 0.00140 & 0.00795 \\
R. semicolorata & 0.0000917 & 0.000121 & 0.0000957 & 0.000160 & 934 & 1500 & 0.0111 & 0.0385 \\
\hline
\end{tabular}

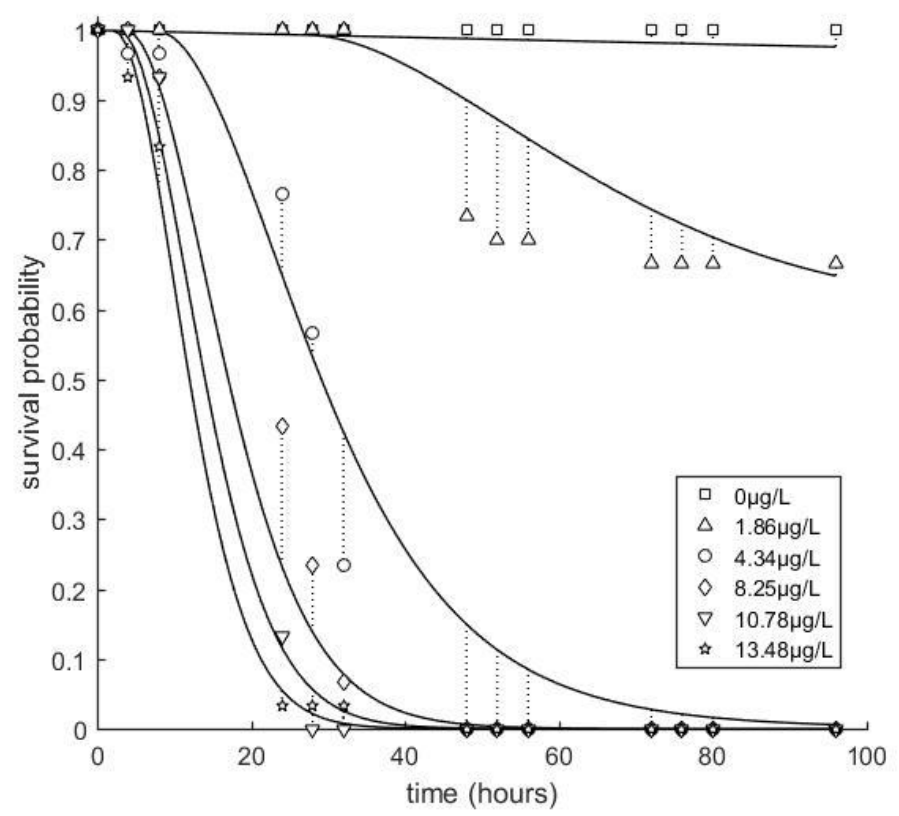

Figure S2: Number of mobile individuals observed in the static acute toxicity test with A. aquaticus; dots and lines represent data and the GUTS model fit respectively; resulting parameter values are listed in Table S13. 


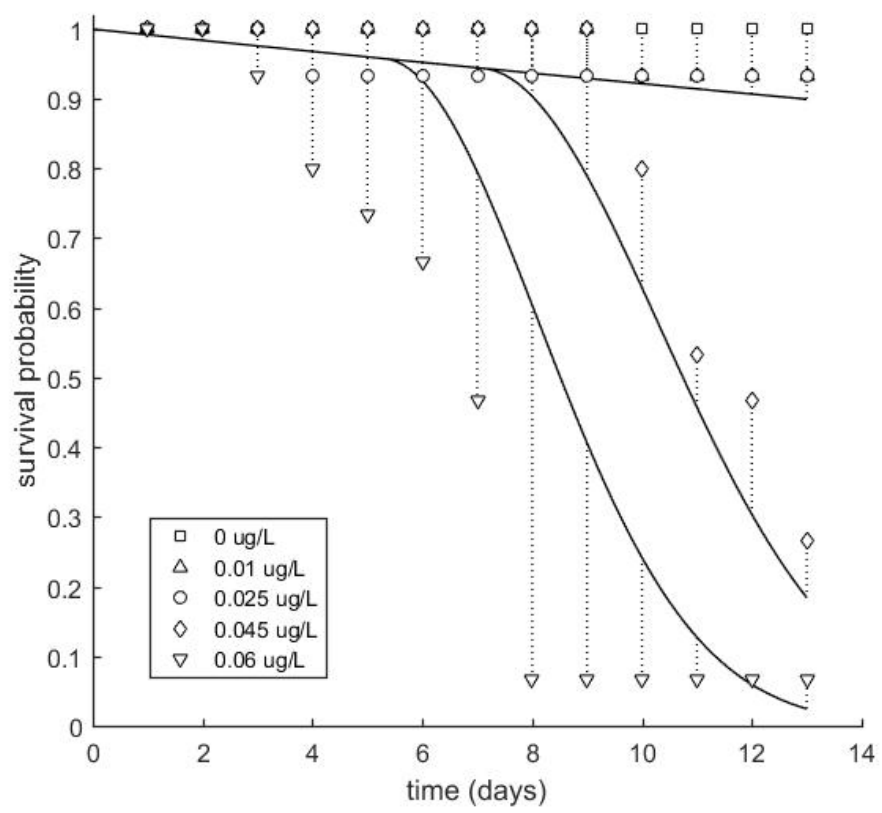

Figure S3: Number of mobile individuals observed in the chronic toxicity test with C. dubia (data from Rose et $\mathrm{al}^{6}{ }^{6}$ ); dots and lines represent data and the GUTS model fit respectively; resulting parameter values are listed in Table S13.

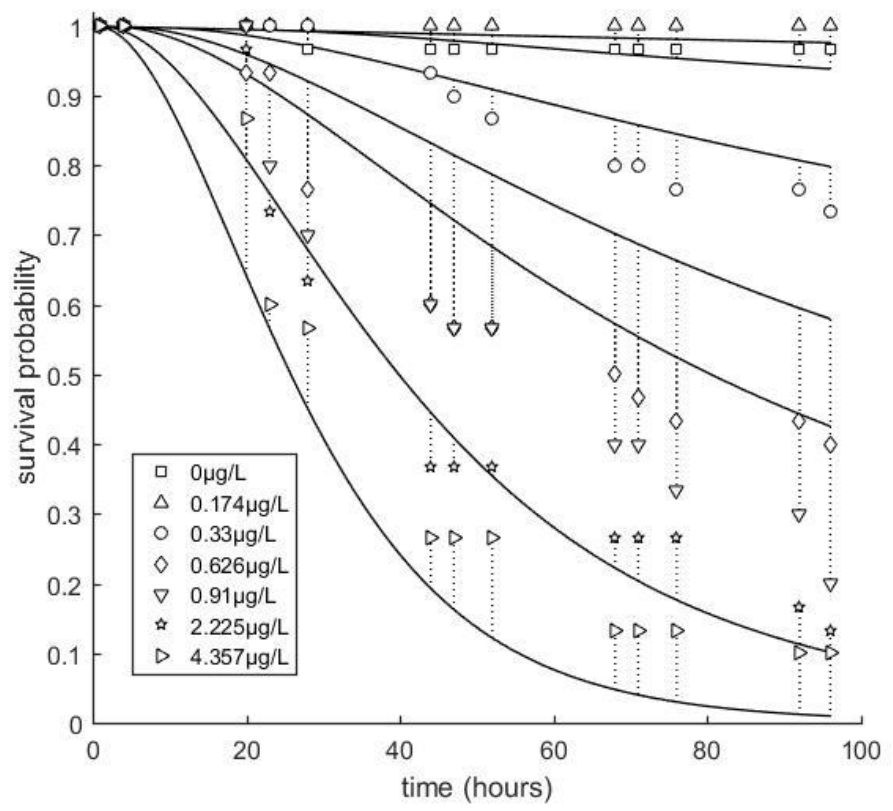

Figure S4: Number of mobile individuals observed in the static acute toxicity test with $C$. crystallinus; dots and lines represent data and the GUTS model fit respectively; resulting parameter values are listed in Table S13. 


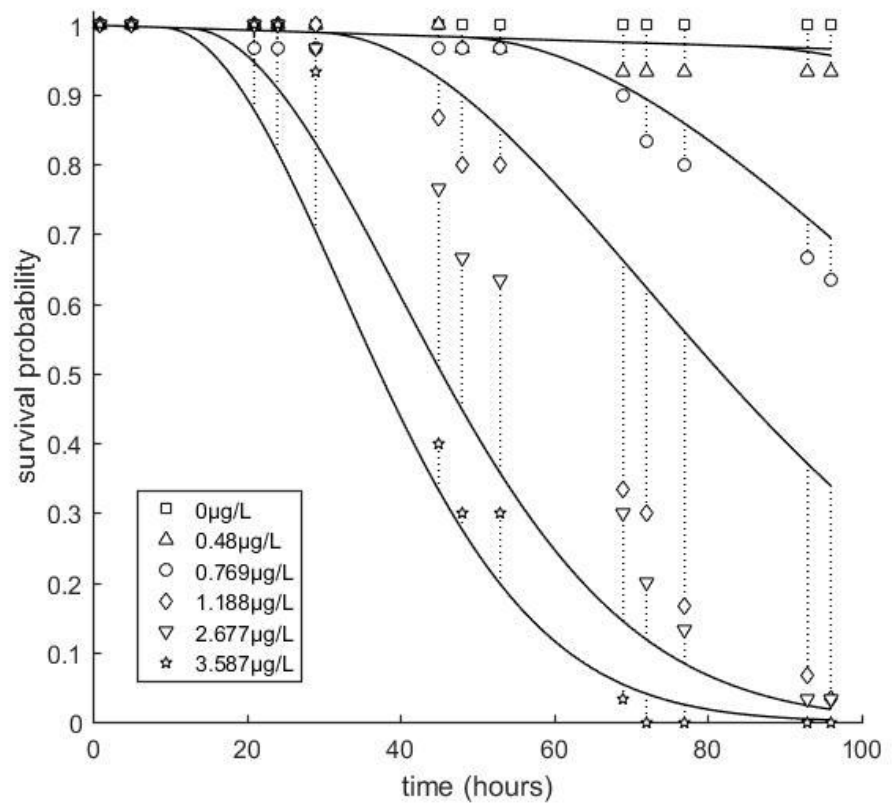

Figure S5: Number of mobile individuals observed in the static acute toxicity test with $C$. dipterum; dots and lines represent data and the GUTS model fit respectively; resulting parameter values are listed in Table S13.

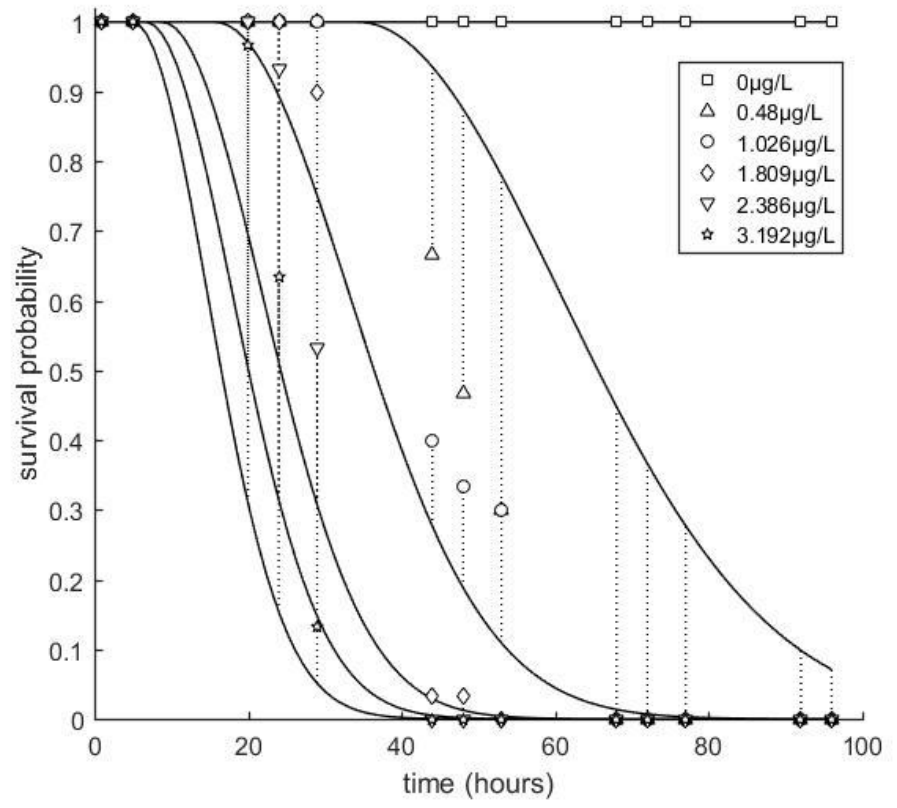

Figure S6: Number of mobile individuals observed in the static acute toxicity test with D. magna at $11.5^{\circ} \mathrm{C}$; dots and lines represent data and the GUTS model fit respectively; resulting parameter values are listed in Table S13. 


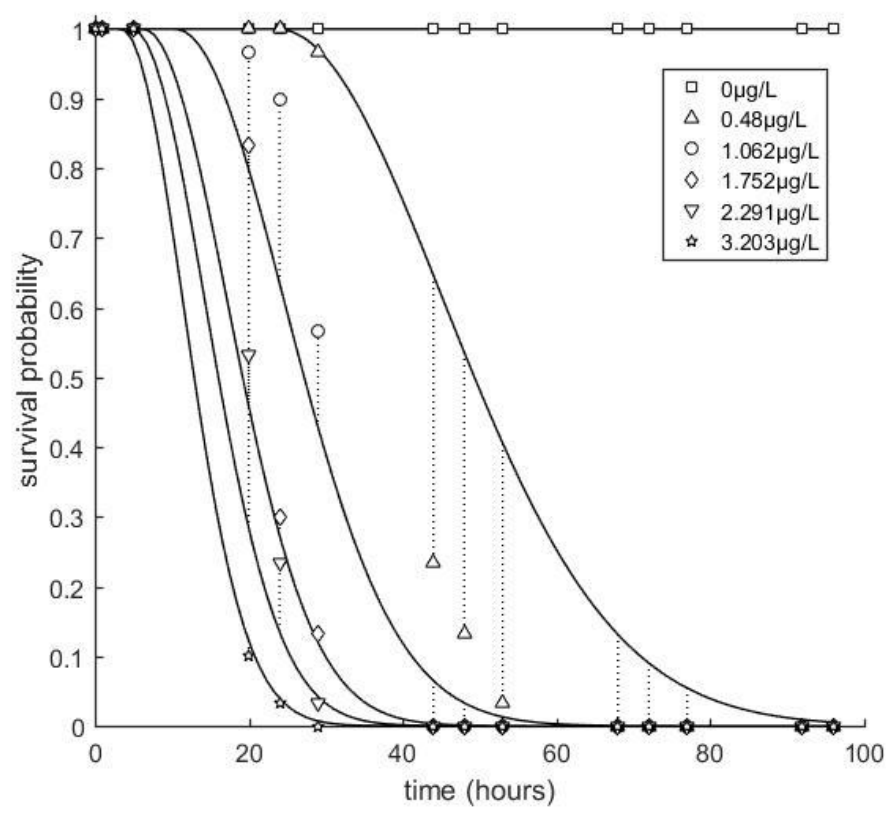

Figure S7: Number of mobile individuals observed in the static acute toxicity test with $D$. magna at $14.9^{\circ} \mathrm{C}$; dots and lines represent data and the GUTS model fit respectively; resulting parameter values are listed in Table $\mathrm{S} 13$.

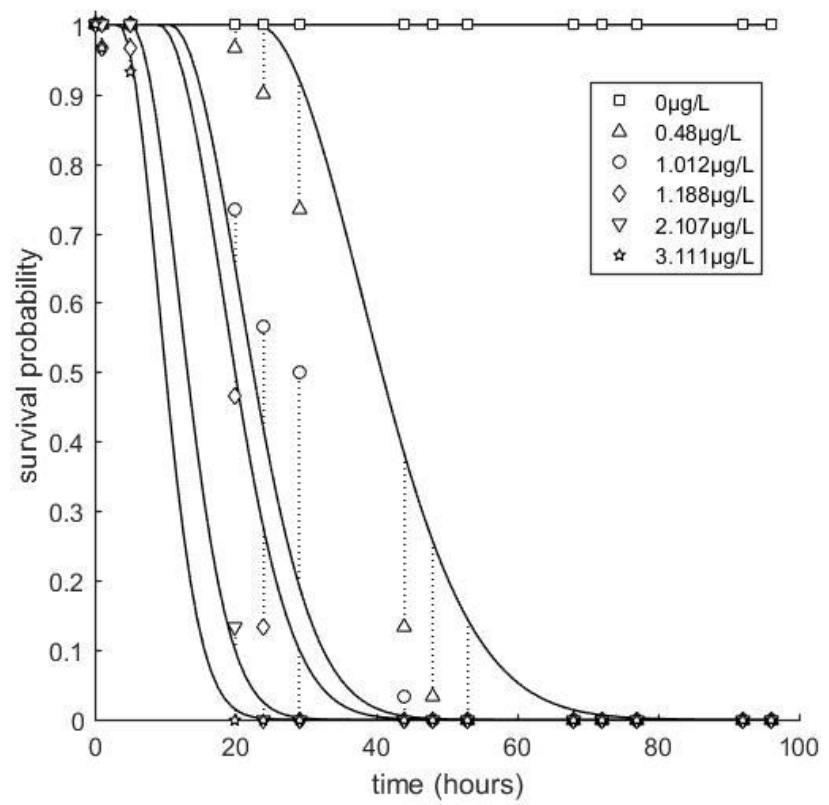

Figure S8: Number of mobile individuals observed in the static acute toxicity test with D. magna at $17.2^{\circ} \mathrm{C}$; dots and lines represent data and the GUTS model fit respectively; resulting parameter values are listed in Table S13. 


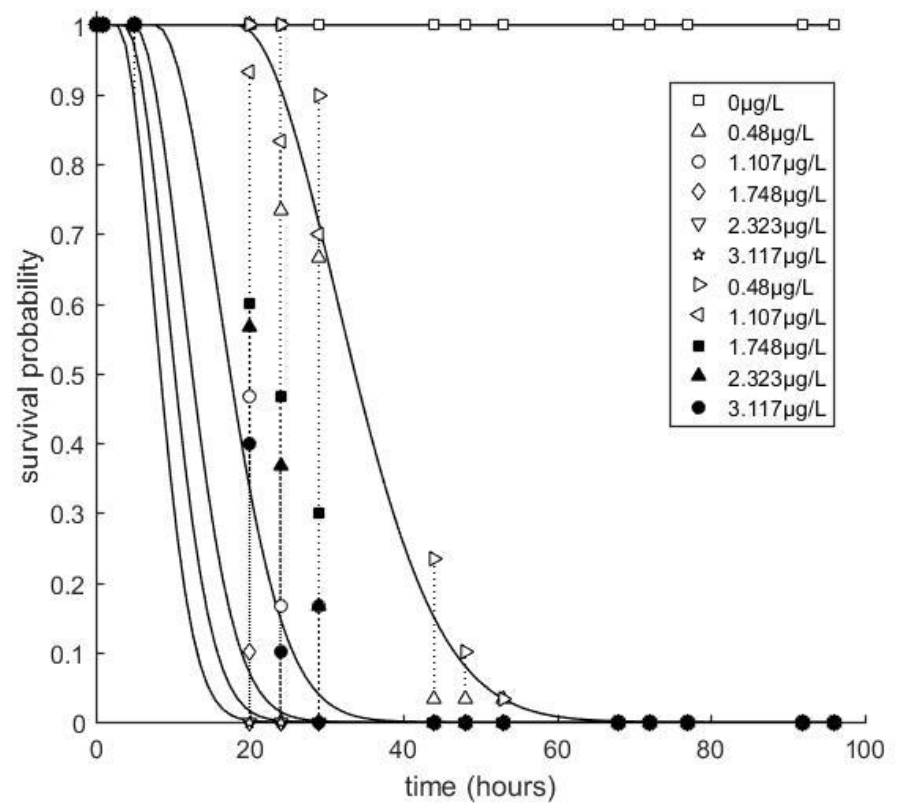

Figure S9: Number of mobile individuals observed in the static acute toxicity test with $D$. magna at $19.8^{\circ} \mathrm{C}$; dots and lines represent data and the GUTS model fit respectively; resulting parameter values are listed in Table S13.

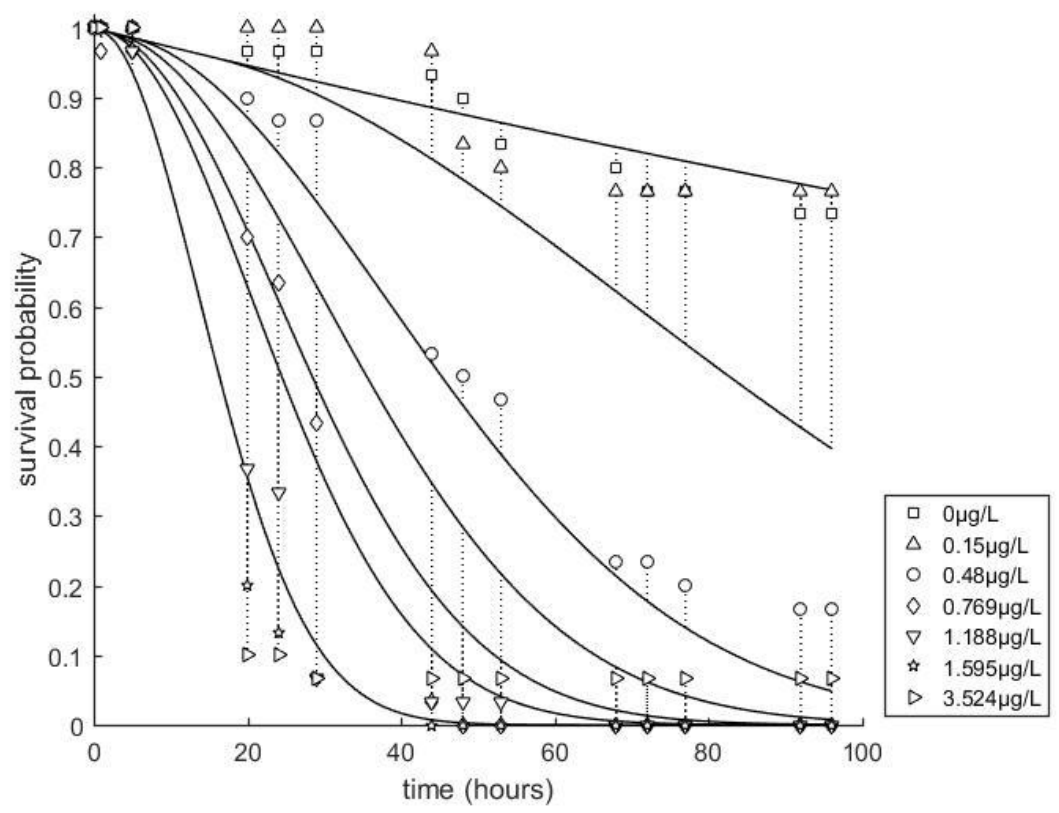

Figure S10: Number of mobile individuals observed in the static acute toxicity test with E. assimilis; dots and lines represent data and the GUTS model fit respectively; resulting parameter values are listed in Table S13. 


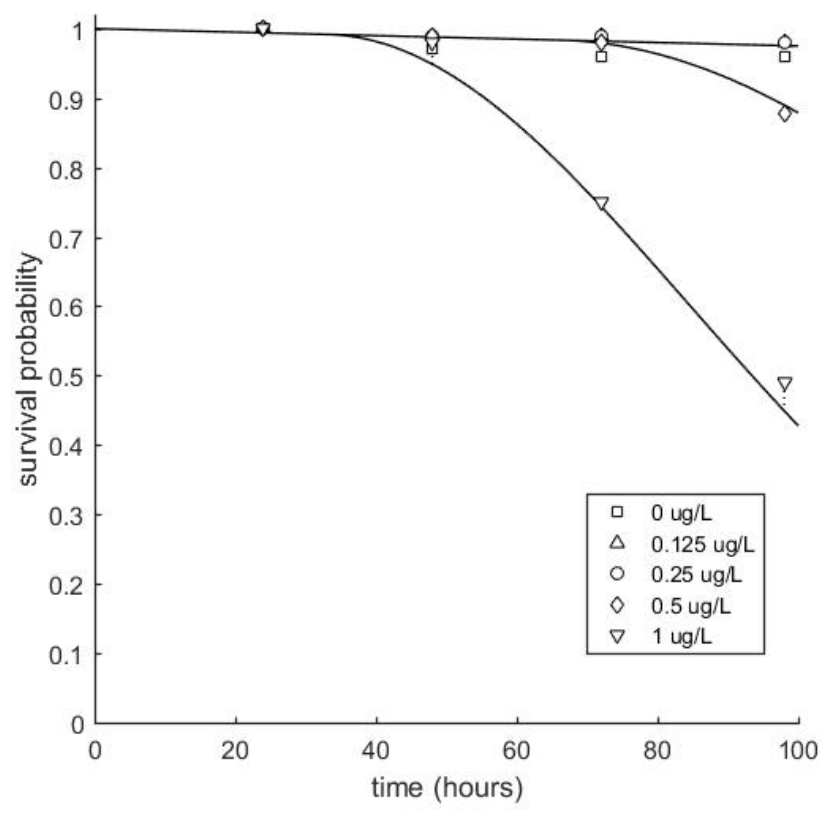

Figure S11: Number of mobile individuals observed in the acute toxicity test with G. fossarum (data from Xuereb et al. ${ }^{7}$ ); dots and lines represent data and the GUTS model fit respectively; resulting parameter values are listed in Table S13.

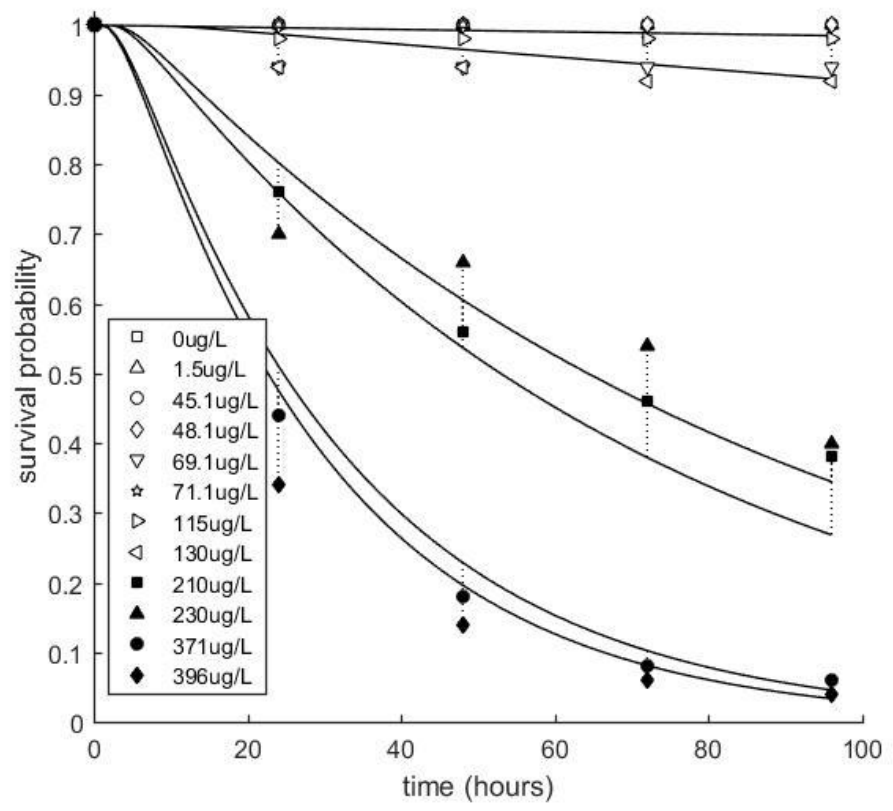

Figure S12: Number of mobile individuals observed in the acute toxicity test with $P$. promelas (data from Brooke et al. ${ }^{8}$ ); dots and lines represent data and the GUTS model fit respectively; resulting parameter values are listed in Table S13. 


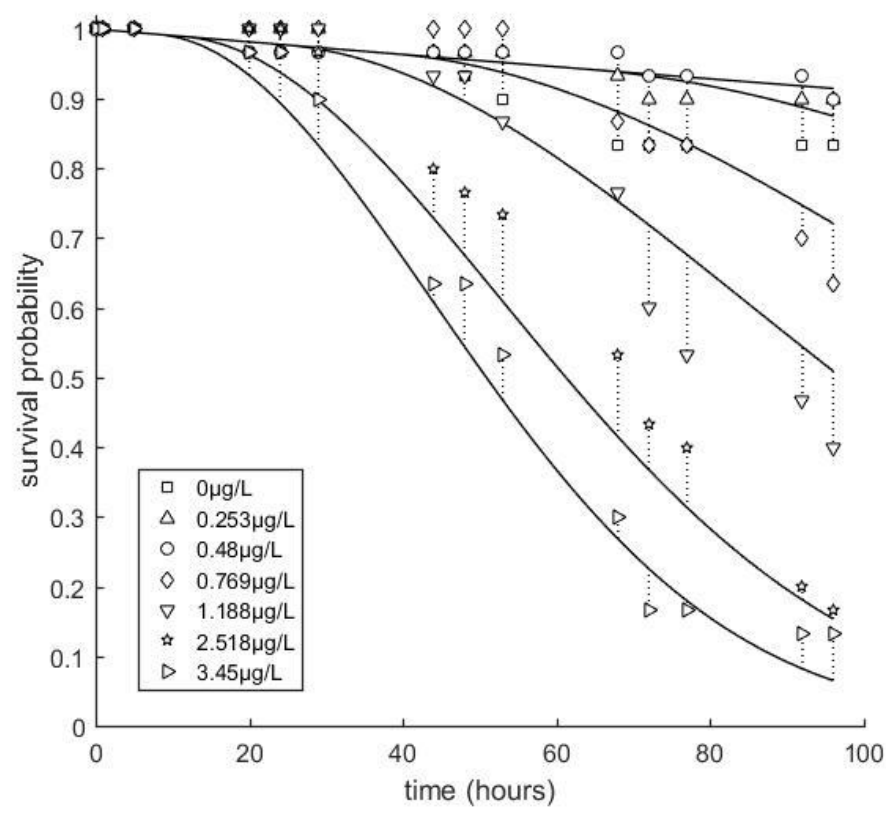

Figure S13: Number of mobile individuals observed in the static acute toxicity test with $R$. semicolorata; dots and lines represent data and the GUTS model fit respectively; resulting parameter values are listed in Table S13.

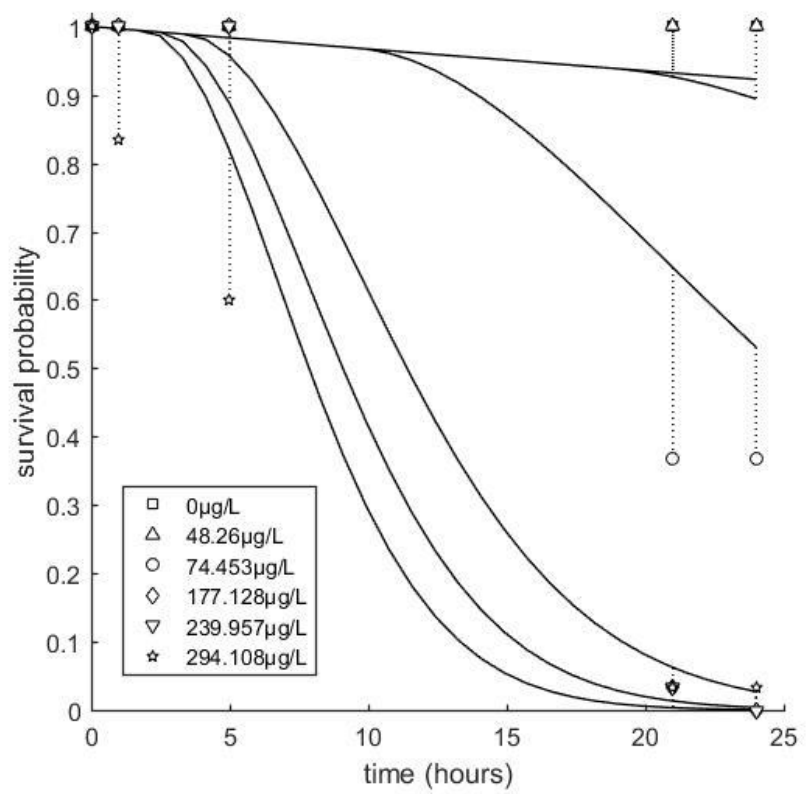

Figure S14: Number of mobile individuals observed in the static acute toxicity test with $P$. antipodarum; dots and lines represent data and the GUTS model fit respectively. The resulting parameter values are listed in Table S13. Please note that 'survival probability' refers to the mobile fraction in the statistical population. As snails started to recover after 24 hours (see Table S10), we have removed the data derived from the later part of the experiment from the GUTS analysis. The exposed snails had been observed to temporarily close their opercula during the latter parts of the experiment, which might have reduced their exposure and facilitated recovery. 


\section{Parameter correlations}
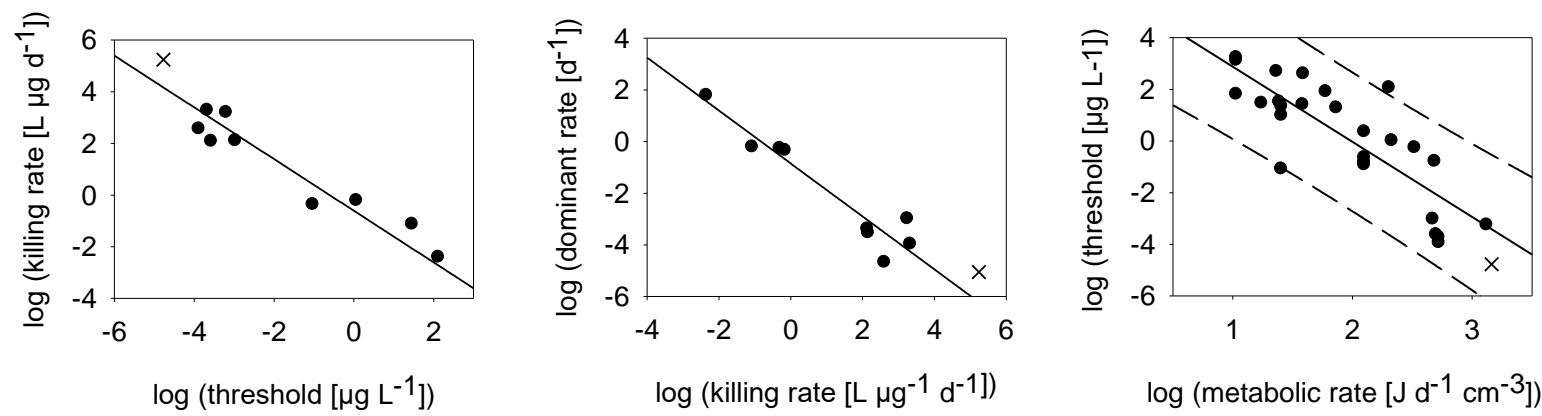

Figure S15: Correlations for GUTS parameters (dots) without consideration of parameters estimated for D. magna (cross) the dominant rate constant $\mathrm{k}_{\mathrm{d}}$ and the killing rate $\mathrm{k}_{\mathrm{k}}$ were corrected for temperature, in addition, $\mathrm{k}_{\mathrm{d}}$ was corrected for body size which corresponds to $\mathrm{k}_{\mathrm{d}} *$ in Equation 2 (see GUTS model description); the threshold refers to parameter $\mathrm{z}$ in Table S13 and the metabolic rate to parameter $\mathrm{p}_{\mathrm{M}}$ in Table S12. Solid lines refer to linear regressions (Parameters in Table S14), while dashed lines in right hand panel represent the $95 \%$ prediction interval.

Table S14: Results of the correlation analysis of TK-TD parameters; y-intercept (y0), slope (a), and the coefficient of correlation $\left(\mathrm{r}^{2}\right)$ are given; please note that log-transformed TK-TD parameter values were used for regression analyses; full regression refers to the analysis including $D$. magna as shown in Figure 3 of the main text, regression without D. magna refers to Figure S15.

\begin{tabular}{lcccccc}
\hline & \multicolumn{3}{c}{ Full regression* } & \multicolumn{3}{c}{ Regression* without D. magna } \\
& $\mathrm{y} 0$ & $\mathrm{a}$ & $\mathrm{r}^{2}$ & $\mathrm{y} 0$ & $\mathrm{a}$ & $\mathrm{r}^{2}$ \\
\hline $\mathrm{k}_{\mathrm{k}}$ Vs z & -0.499 & -1 & 0.91 & -0.607 & -1 & 0.90 \\
$\mathrm{k}_{\mathrm{d}}$ Vs. $\mathrm{k}_{\mathrm{k}}$ & 0.861 & -0.936 & 0.90 & -0.849 & -1.02 & 0.91 \\
$\mathrm{z}$ vs. $\mathrm{p}_{\mathrm{M}}$ & 6.02 & -3.05 & 0.71 & 5.79 & -2.91 & 0.68 \\
\hline
\end{tabular}

$\mathrm{k}_{\mathrm{k}}$ : killing rate, $\mathrm{z}$ : threshold for the effect, $\mathrm{k}_{\mathrm{d}}$ : dominant rate constant, $\mathrm{p}_{\mathrm{M}}$ : metabolic rate, *regression: $\mathrm{y}=\mathrm{y} 0+\mathrm{ax}$ 


\section{Results from population experiments}

Table S15: Number of neonates, juveniles and adults in the population experiments with D. magna under control conditions. The experiment had been replicated four times (R1-R4)

\begin{tabular}{|c|c|c|c|c|}
\hline Replicate & Time $[\mathrm{d}]$ & Neonates & Juveniles & Adults \\
\hline R1 & 0 & 5 & 0 & 3 \\
\hline $\mathrm{R} 1$ & 3 & 7 & 18 & 3 \\
\hline $\mathrm{R} 1$ & 7 & 18 & 82 & 11 \\
\hline $\mathrm{R} 1$ & 10 & 17 & 135 & 12 \\
\hline $\mathrm{R} 1$ & 14 & 6 & 164 & 18 \\
\hline $\mathrm{R} 1$ & 17 & 8 & 168 & 12 \\
\hline $\mathrm{R} 1$ & 21 & 14 & 155 & 16 \\
\hline $\mathrm{R} 1$ & 23 & 3 & 130 & 15 \\
\hline $\mathrm{R} 1$ & 28 & 2 & 105 & 21 \\
\hline $\mathrm{R} 1$ & 31 & 7 & 100 & 22 \\
\hline $\mathrm{R} 1$ & 35 & 0 & 102 & 21 \\
\hline $\mathrm{R} 2$ & 3 & 14 & 26 & 3 \\
\hline $\mathrm{R} 2$ & 7 & 0 & 55 & 13 \\
\hline $\mathrm{R} 2$ & 10 & 7 & 114 & 19 \\
\hline $\mathrm{R} 2$ & 14 & 5 & 112 & 28 \\
\hline $\mathrm{R} 2$ & 17 & 4 & 129 & 19 \\
\hline $\mathrm{R} 2$ & 21 & 7 & 127 & 19 \\
\hline $\mathrm{R} 2$ & 23 & 2 & 121 & 19 \\
\hline $\mathrm{R} 2$ & 28 & 2 & 109 & 22 \\
\hline $\mathrm{R} 2$ & 31 & 5 & 113 & 26 \\
\hline $\mathrm{R} 2$ & 35 & 2 & 110 & 24 \\
\hline $\mathrm{R} 3$ & 3 & 6 & 22 & 3 \\
\hline $\mathrm{R} 3$ & 7 & 20 & 65 & 14 \\
\hline $\mathrm{R} 3$ & 10 & 13 & 111 & 14 \\
\hline $\mathrm{R} 3$ & 14 & 5 & 141 & 16 \\
\hline $\mathrm{R} 3$ & 17 & 8 & 151 & 18 \\
\hline $\mathrm{R} 3$ & 21 & 5 & 140 & 17 \\
\hline $\mathrm{R} 3$ & 23 & 1 & 121 & 15 \\
\hline $\mathrm{R} 3$ & 28 & 0 & 83 & 27 \\
\hline R3 & 31 & 9 & 113 & 23 \\
\hline $\mathrm{R} 3$ & 35 & 0 & 115 & 25 \\
\hline $\mathrm{R} 4$ & 3 & 4 & 23 & 3 \\
\hline $\mathrm{R} 4$ & 7 & 8 & 74 & 12 \\
\hline $\mathrm{R} 4$ & 10 & 15 & 86 & 13 \\
\hline $\mathrm{R} 4$ & 14 & 5 & 122 & 18 \\
\hline $\mathrm{R} 4$ & 17 & 8 & 102 & 19 \\
\hline $\mathrm{R} 4$ & 21 & 2 & 120 & 15 \\
\hline $\mathrm{R} 4$ & 23 & 1 & 113 & 17 \\
\hline $\mathrm{R} 4$ & 28 & 1 & 91 & 28 \\
\hline $\mathrm{R} 4$ & 31 & 12 & 117 & 25 \\
\hline $\mathrm{R} 4$ & 35 & 2 & 121 & 25 \\
\hline
\end{tabular}


Table S16: Number of neonates, juveniles and adults in the population experiments with D. magna under single peak exposure. The experiment had been replicated four times (R1-R4).

\begin{tabular}{|c|c|c|c|c|}
\hline Replicate & Time $[\mathrm{d}]$ & Neonates & Juveniles & Adults \\
\hline $\mathrm{R} 1$ & 0 & 5 & 0 & 3 \\
\hline $\mathrm{R} 1$ & 3 & 13 & 28 & 3 \\
\hline $\mathrm{R} 1$ & 7 & 3 & 68 & 17 \\
\hline $\mathrm{R} 1$ & 10 & 3 & 114 & 27 \\
\hline $\mathrm{R} 1$ & 14 & 10 & 139 & 22 \\
\hline $\mathrm{R} 1$ & 17 & 2 & 134 & 18 \\
\hline $\mathrm{R} 1$ & 21 & 7 & 112 & 18 \\
\hline $\mathrm{R} 1$ & 23 & 0 & 3 & 5 \\
\hline $\mathrm{R} 1$ & 28 & 0 & 0 & 0 \\
\hline $\mathrm{R} 1$ & 31 & 0 & 0 & 0 \\
\hline $\mathrm{R} 1$ & 35 & 0 & 0 & 0 \\
\hline $\mathrm{R} 2$ & 3 & 17 & 24 & 3 \\
\hline $\mathrm{R} 2$ & 7 & 8 & 68 & 15 \\
\hline $\mathrm{R} 2$ & 10 & 11 & 117 & 16 \\
\hline $\mathrm{R} 2$ & 14 & 7 & 154 & 21 \\
\hline $\mathrm{R} 2$ & 17 & 4 & 128 & 23 \\
\hline $\mathrm{R} 2$ & 21 & 6 & 130 & 13 \\
\hline $\mathrm{R} 2$ & 23 & 0 & 3 & 3 \\
\hline $\mathrm{R} 2$ & 28 & 0 & 0 & 0 \\
\hline $\mathrm{R} 2$ & 31 & 0 & 0 & 0 \\
\hline $\mathrm{R} 2$ & 35 & 0 & 0 & 0 \\
\hline $\mathrm{R} 3$ & 3 & 4 & 31 & 3 \\
\hline $\mathrm{R} 3$ & 7 & 21 & 79 & 13 \\
\hline $\mathrm{R} 3$ & 10 & 12 & 138 & 16 \\
\hline $\mathrm{R} 3$ & 14 & 4 & 157 & 21 \\
\hline $\mathrm{R} 3$ & 17 & 5 & 182 & 12 \\
\hline $\mathrm{R} 3$ & 21 & 6 & 116 & 11 \\
\hline $\mathrm{R} 3$ & 23 & 0 & 4 & 3 \\
\hline $\mathrm{R} 3$ & 28 & 0 & 0 & 0 \\
\hline $\mathrm{R} 3$ & 31 & 0 & 0 & 0 \\
\hline $\mathrm{R} 3$ & 35 & 0 & 0 & 0 \\
\hline $\mathrm{R} 4$ & 3 & 6 & 27 & 3 \\
\hline $\mathrm{R} 4$ & 7 & 15 & 67 & 11 \\
\hline $\mathrm{R} 4$ & 10 & 30 & 109 & 17 \\
\hline $\mathrm{R} 4$ & 14 & 18 & 139 & 20 \\
\hline $\mathrm{R} 4$ & 17 & 7 & 127 & 18 \\
\hline $\mathrm{R} 4$ & 21 & 5 & 107 & 13 \\
\hline $\mathrm{R} 4$ & 23 & 0 & 3 & 7 \\
\hline $\mathrm{R} 4$ & 28 & 0 & 0 & 0 \\
\hline $\mathrm{R} 4$ & 31 & 0 & 0 & 0 \\
\hline $\mathrm{R} 4$ & 35 & 0 & 0 & 0 \\
\hline
\end{tabular}


Table S17: Number of neonates, juveniles and adults in the population experiments with $D$. magna under double peak exposure. The experiment was replicated four times (R1-R4).

\begin{tabular}{|c|c|c|c|c|}
\hline Replicate & Time $[\mathrm{d}]$ & Neonates & Juveniles & Adults \\
\hline R1 & 0 & 5 & 0 & 3 \\
\hline $\mathrm{R} 1$ & 3 & 5 & 18 & 3 \\
\hline $\mathrm{R} 1$ & 7 & 0 & 7 & 1 \\
\hline $\mathrm{R} 1$ & 10 & 0 & 5 & 2 \\
\hline $\mathrm{R} 1$ & 14 & 0 & 17 & 8 \\
\hline $\mathrm{R} 1$ & 17 & 49 & 77 & 8 \\
\hline $\mathrm{R} 1$ & 21 & 36 & 166 & 8 \\
\hline $\mathrm{R} 1$ & 23 & 2 & 9 & 3 \\
\hline $\mathrm{R} 1$ & 28 & 0 & 2 & 0 \\
\hline $\mathrm{R} 1$ & 31 & 0 & 0 & 2 \\
\hline $\mathrm{R} 1$ & 35 & 12 & 22 & 2 \\
\hline $\mathrm{R} 2$ & 3 & 17 & 9 & 3 \\
\hline $\mathrm{R} 2$ & 7 & 1 & 24 & 0 \\
\hline $\mathrm{R} 2$ & 10 & 2 & 9 & 15 \\
\hline $\mathrm{R} 2$ & 14 & 21 & 8 & 18 \\
\hline $\mathrm{R} 2$ & 17 & 59 & 61 & 20 \\
\hline $\mathrm{R} 2$ & 21 & 21 & 135 & 20 \\
\hline $\mathrm{R} 2$ & 23 & 9 & 1 & 10 \\
\hline $\mathrm{R} 2$ & 28 & 0 & 3 & 0 \\
\hline $\mathrm{R} 2$ & 31 & 0 & 0 & 3 \\
\hline $\mathrm{R} 2$ & 35 & 8 & 20 & 3 \\
\hline R3 & 3 & 1 & 15 & 3 \\
\hline R3 & 7 & 0 & 4 & 0 \\
\hline R3 & 10 & 1 & 3 & 0 \\
\hline $\mathrm{R} 3$ & 14 & 4 & 11 & 3 \\
\hline R3 & 17 & 15 & 200 & 4 \\
\hline $\mathrm{R} 3$ & 21 & 20 & 184 & 4 \\
\hline R3 & 23 & 2 & 0 & 0 \\
\hline R3 & 28 & 0 & 1 & 0 \\
\hline R3 & 31 & 0 & 0 & 1 \\
\hline $\mathrm{R} 3$ & 35 & 33 & 3 & 1 \\
\hline $\mathrm{R} 4$ & 3 & 3 & 13 & 2 \\
\hline $\mathrm{R} 4$ & 7 & 0 & 4 & 1 \\
\hline $\mathrm{R} 4$ & 10 & 0 & 0 & 4 \\
\hline $\mathrm{R} 4$ & 14 & 25 & 39 & 4 \\
\hline $\mathrm{R} 4$ & 17 & 19 & 62 & 3 \\
\hline $\mathrm{R} 4$ & 21 & 25 & 117 & 6 \\
\hline $\mathrm{R} 4$ & 23 & 3 & 15 & 3 \\
\hline $\mathrm{R} 4$ & 28 & 0 & 0 & 0 \\
\hline $\mathrm{R} 4$ & 31 & 0 & 0 & 0 \\
\hline $\mathrm{R} 4$ & 35 & 0 & 0 & 0 \\
\hline
\end{tabular}




\section{Population modeling}

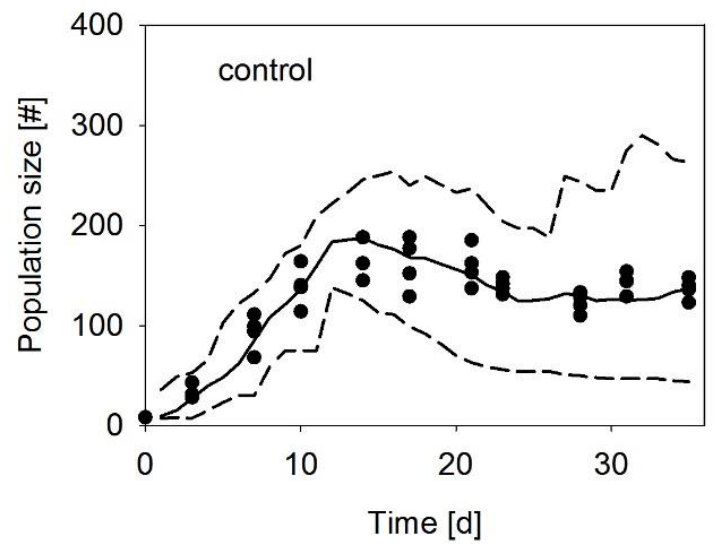

Figure S16: Prediction of the total D. magna population size for the control scenario. Dots represent data, solid lines give the mean and dashed lines the range of simulation results.
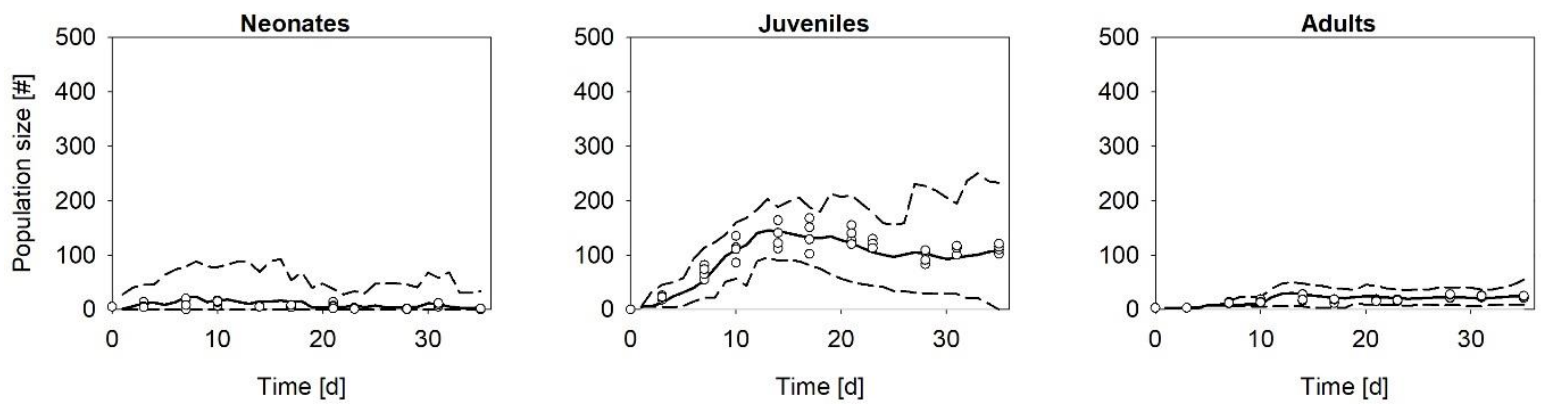

Figure S17: Population level predictions for the control scenario. Dots represent data, solid lines give the mean and dashed lines the range of simulation results for neonates, juveniles and adults of $D$. magna. 

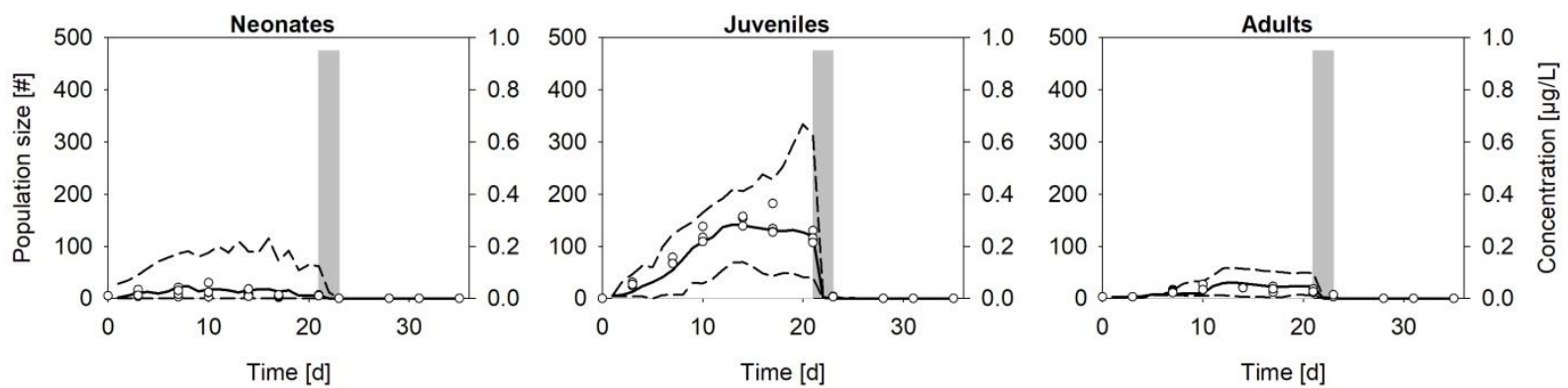

Figure S18: Population level predictions for D. magna and a single peak exposure scenario. Prediction based on the actual GUTS parameterization for $\boldsymbol{D}$. magna. Data and simulations for the control are shown in Figure S17. Dots represent data, gray bars indicate exposure concentrations, solid lines give the mean and dashed lines the range of simulation results for neonates, juveniles and adults.
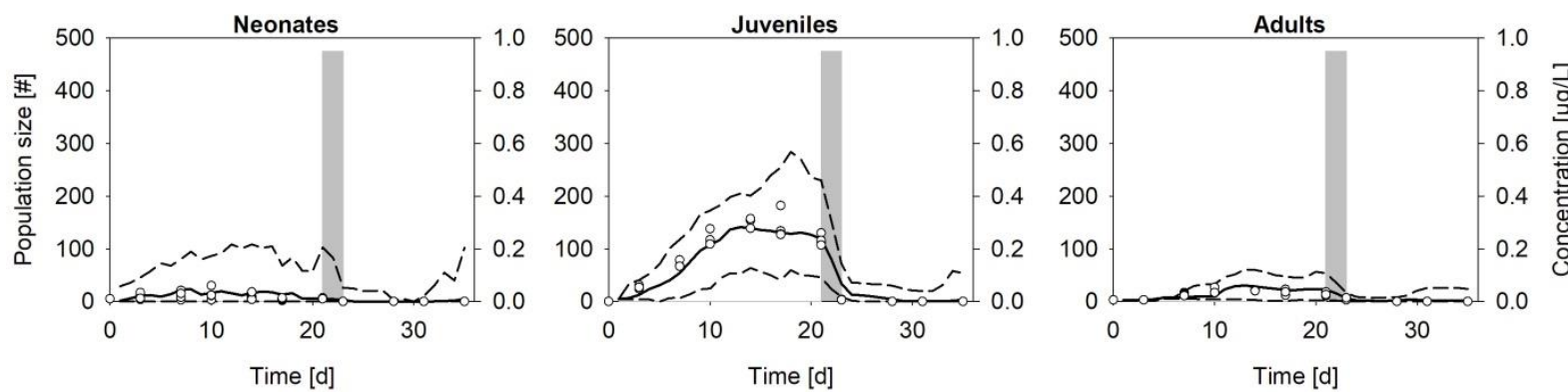

Figure S19: Population level predictions for D. magna and a single peak exposure scenario.

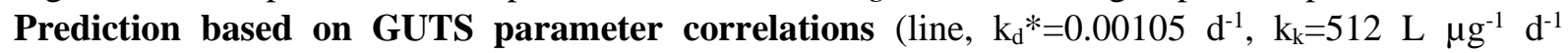
$\mathrm{z}=0.000387 \mu \mathrm{g} \mathrm{L}^{-1}$ ). Data and simulations for the control are shown in Figure S17. Dots represent data, gray bars indicate exposure concentrations, solid lines give the mean and dashed lines the range of simulation results for neonates, juveniles and adults.
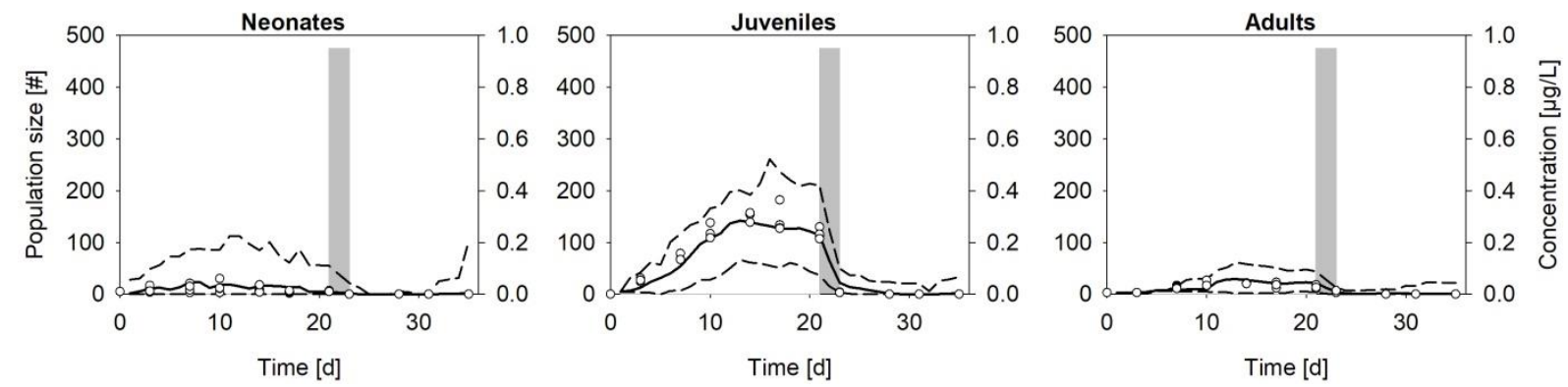

Figure S20: Population level predictions for D. magna and a single peak exposure scenario. Prediction based on GUTS parameter correlations and reduced threshold (i.e. the lower $95 \%$ prediction interval for $\mathrm{z})$ is used $\left(\mathrm{k}_{\mathrm{d}}{ }^{*}=0.00105 \mathrm{~d}^{-1}, \mathrm{k}_{\mathrm{k}}=512 \mathrm{~L} \mathrm{\mu g}^{-1} \mathrm{~d}^{-1} \mathrm{z}=0.000000575 \mu \mathrm{g} \mathrm{L}^{-1}\right)$; see main text for further explanation. Data and simulations for the control are shown in Figure S17. Dots represent data, gray bars indicate exposure concentrations, solid lines give the mean and dashed lines the range of simulation results for neonates, juveniles and adults. 

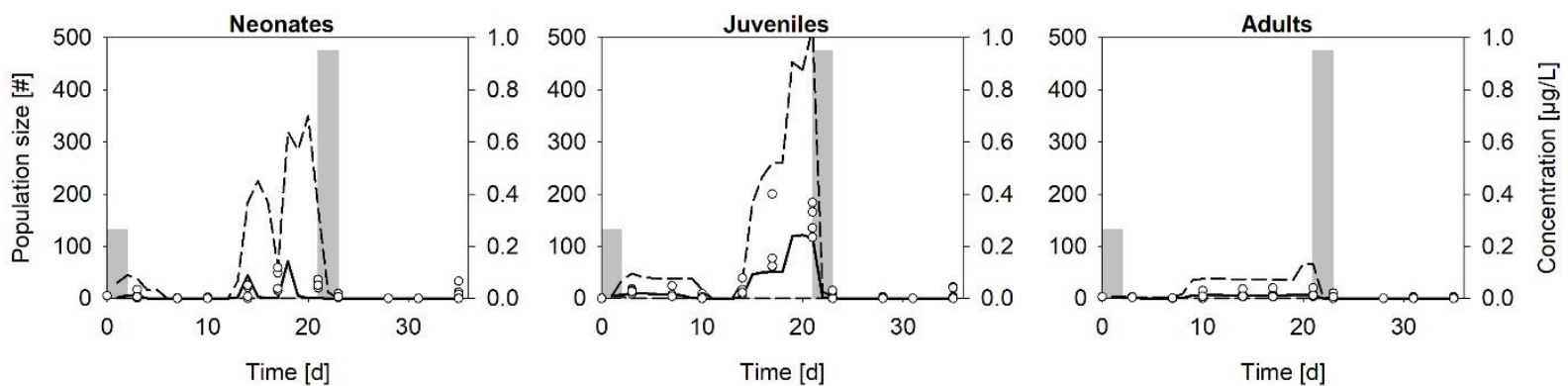

Figure S21: Population level predictions for D. magna and a double peak exposure scenario. Prediction based on the actual GUTS parameterization for $D$. magna. Data and simulations for the control are shown in Figure S17. Dots represent data, gray bars indicate exposure concentrations, solid lines give the mean and dashed lines the range of simulation results for neonates, juveniles and adults.
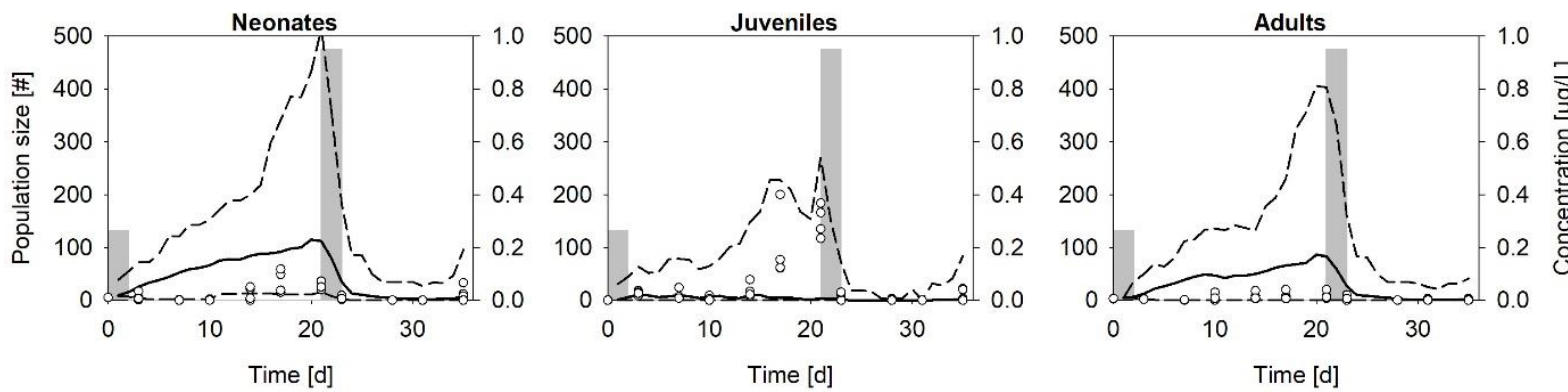

Figure S22: Population level predictions for D. magna and a double peak exposure scenario.

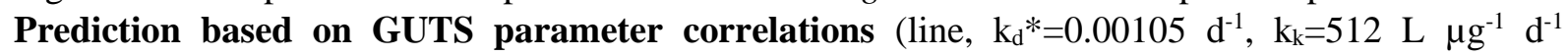
$\mathrm{z}=0.000387 \mu \mathrm{g} \mathrm{L}^{-1}$ ). Data and simulations for the control are shown in Figure S17. Dots represent data, gray bars indicate exposure concentrations, solid lines give the mean and dashed lines the range of simulation results for neonates, juveniles and adults.
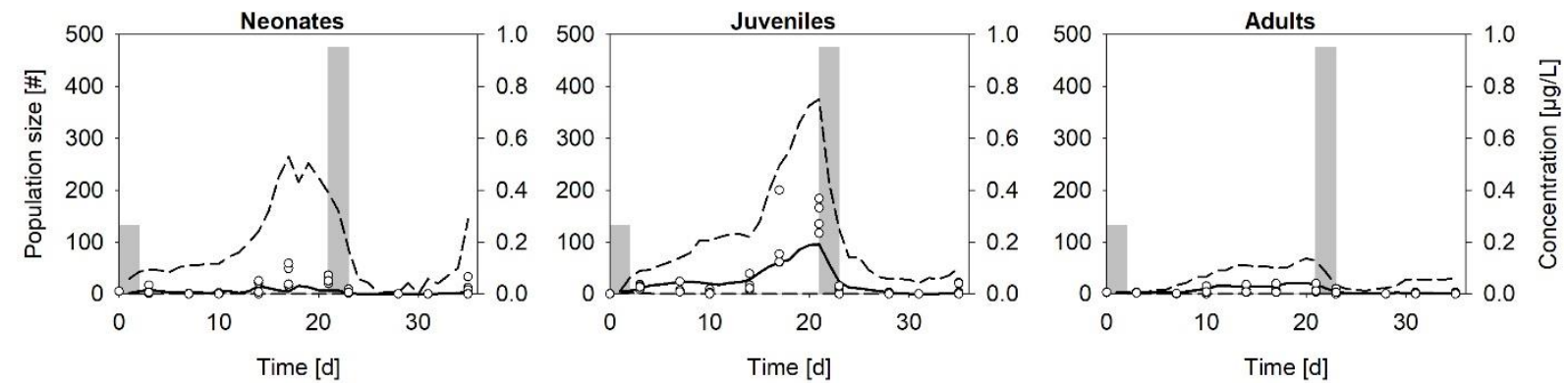

Figure S23: Population level predictions for D. magna and a double peak exposure scenario. Prediction based on GUTS parameter correlations and reduced threshold (i.e. the lower 95\%

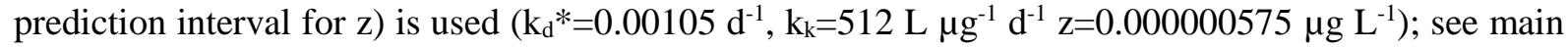
text for further explanation. Data and simulations for the control are shown in Figure S17. Dots represent data, gray bars indicate exposure concentrations, solid lines give the mean and dashed lines the range of simulation results for neonates, juveniles and adults. 


\section{References}

(1) Jager, T.; Ashauer, R. Modelling survival under chemical stress. A comprehensive guide to the GUTS framework. Version 1.0. Toxicodynamics Ltd., York, UK. 2018. Available from Leanpub: https://leanpub.com/guts_book.

(2) AmP 2018. Add-my-pet database of code, data and DEB model parameters: https://bio.vu.nl/thb/deb/deblab/add_my_pet/index.html, accessed on 01/14/2018

(3) Kon Kam King, G., Veber, P., Charles, S., Delignette-Muller, M.L. MOSAIC_SSD: a new web tool for species sensitivity distribution to include censored data by maximum likelihood.

Environmental Toxicology and Chemistry 2014, 33, 2133-2139.

http://pbil.univ-lyon1.fr/software/mosaic/ssd/

(4) Baas, J.; Kooijman, S. A. L. M. Sensitivity of animals to chemical compounds links to metabolic rate. Ecotoxicology 2015, 24, 657-663.

(5) Barata, C.; Alanon, P.; Gutierrez-Alonso, S.; Riva, M. C.; Fernandez, C.; Tarazona, J. V. A Daphnia magna feeding bioassay as a cost effective and ecological relevant sublethal toxicity test for Environmental Risk Assessment of toxic effluents. Science of the Total Environment 2008, 405, 7886. DOI 10.1016/j.scitotenv.2008.06.028

(6) Rose, R. M.; Warne, M. St. J.; Lim, R. P. Food concentration affects the life history response of Ceriodaphnia cf. dubia to chemicals with different mechanisms of action. Ecotoxicology and Environmental Safety 2002, 51, 106-114.

(7) Xuereb, M.; Lefevre, E.; Garric, J.; Geffard, O. Acetylcholinesterase activity in Gammarus fossarum (Crustacea Amphipoda): Linking AChE inhibition and behavioral alteration. Aquatic Toxicology 2009, 94, 114-122.

(8) Brooke, L.T.; Call, D.J.; Geiger, D.L.; Nothcott, C.E., Eds. Acute toxicities of organic chemicals to fathead minnows (Pimephales promelas). Center for Lake Superior Environmental Studies, University of Wisconsin-Superior, 1984 